Marquette University

e-Publications@Marquette

Psychology Faculty Research and Publications

Psychology Department

3-1-2002

\title{
Differences in the Functional Neuroanatomy of Inhibitory Control Across the Adult Life Span
}

Kristy A. Nielson

Marquette University, kristy.nielson@marquette.edu

Scott Aaron Langenecker

University of Michigan - Ann Arbor

Hugh Garavan

Marquette University

Accepted version. Psychology and Aging, Vol. 17, No. 1 (March 2002): 56-71. DOI. (C) 2002 American Psychological Association. Used with permission. 


\title{
Differences in the Functional Neuroanatomy of Inhibitory Control Across the Adult Life Span
}

\author{
Kristy A. Nielson \\ Department of Psychology, Integrative Neuroscience Research \\ Center, Marquette University \\ Department of Psychiatry and Behavioral Medicine, Medical \\ College of Wisconsin, Foley Center for Aging and Development, \\ Medical College of Wisconsin \\ Milwaukee, WI \\ Scott A. Langenecker \\ Department of Psychology, Marquette University, \\ Miwaukee, WI \\ Hugh Garavan \\ Department of Psychiatry and Behavioral Medicine, \\ Medical College of Wisconsin, \\ Milwaukee, WI \\ Department of Psychology, Trinity College, \\ Dublin, I reland
}

Psychology and Aging, Vol 17, No. 1 (March 2002): pg. 56-71. DOI. This article is @ American Psychological Association and permission has been granted for this version to appear in e-Publications@Marquette. American Psychological Association does not grant permission for this article to be further copied/distributed or hosted elsewhere without the express permission from American Psychological Association. 
The neuropsychological literature has identified declines with "normal" aging that span multiple cognitive domains (e.g., Craik \& Salthouse, 1992; Light, 1996; Woodruff-Pak, 1997), but little is known about the etiology of such declines. It is possible that cognitive losses are the result of changes in a common underlying mechanism, such as declining processing speed (for a review, see Salthouse, 1996) or inhibitory control (e.g., Hasher \& Zacks, 1988). For example, selective attention to a subset of a complex environment, activation of appropriate meanings during language and text comprehension, and activation of appropriate memories at encoding and retrieval all depend on a person's ability to suppress interfering stimuli, interpretations, and memories, respectively (see Dempster \& Brainerd, 1995). As such, cognitive inhibition is receiving particularly strong interest in the developmental literature, at both ends of the life span, as a possible underpinning of developmental changes in cognition (Bjorklund \& Harnishfeger, 1995; Brainerd \& Reyna, 1993; Dempster, 1993; Diamond, 1990; Hasher \& Zacks, 1988).

Much evidence of inhibitory decline in aging has come to light in recent years, although the finding is far from universal (cf. McDowd, Oseas-Kreger, \& Filion, 1995). For example, studies show that older adults experience more intrusions of task-irrelevant information (e.g., G. Cohen, 1988), more interference when learning a new task that competes with a previously learned response (Kausler \& Hakami, 1982), and more perseveration when learning a new categorical response contingency (Haaland, Vranes, Goodwin, \& Garry, 1987). Indeed, older humans and nonhuman animals demonstrate deficits in inhibitory function in a number of domains, including comparable processing of relevant and irrelevant sensory stimuli (cf. McDowd et al., 1995), decreased latent inhibition (Misanin, Blatt, \& Hinderliter, 1985), reduced or slowed habituation (McDowd \& Filion, 1992), and increased intrusive thoughts (Hashtroudi, Johnson, \& Chrosniak, 1990). In addition, in some studies of older adults, it appears that there is increased difficulty in shifting set (Benton, Eslinger, \& Damasio, 1981; Leach, Warner, Hotz-Sud, Kaplan, \& Freedman, 1991) and that irrelevant information persists in working memory to compete with relevant information (e.g., Hamm \& Hasher, 1992; Hartman \& Hasher, 1991). Other inhibition-related tasks have produced more variable results in elders. Specifically, some studies show increased semantic interference (e.g., the "Stroop effect," $\underline{N}$. Cohen, Dustman, \&

Psychology and Aging, Vol 17, No. 1 (March 2002): pg. 56-71. DOI. This article is (c) American Psychological Association and permission has been granted for this version to appear in e-Publications@Marquette. American Psychological Association does not grant permission for this article to be further copied/distributed or hosted elsewhere without the express permission from American Psychological Association. 
Bradford 1984; Houx, Jolles, \& Vreling, 1993; Panek, Rush, \& Slade, 1984) and decreased negative priming (e.g., Fox, 1995; McDowd \& Oseas-Kreger, 1991), whereas others have found no such declines (e.g., Kieley \& Hartley, 1997; Little \& Hartley, 2000; Verhaeghen \& de Meersman, 1998)

The variability in findings of inhibitory function in aging might result from differences across tasks. Inhibition is often considered an "executive function" (cf. Lezak, 1995), but there is controversy over the unity or diversity of such functions and their neuroanatomical bases (e.g., Duncan, Johnson, Swales, \& Freer, 1997; Miyake, Friedman, Emerson, Witzki, \& Howerter, 2000; Teuber, 1972). For example, a recent study showed that there are at least three correlated but separable "executive" constructs: mental task- or setshifting, information updating and monitoring, and inhibition (Miyake et al., 2000). As such, it may be that "inhibition" is not a single construct and that aging might affect various inhibition subtypes differentially. Sensory and motoric inhibition tasks, however, have shown fairly consistent age-related decline (cf. McDowd et al., 1995).

The functional neuroanatomy of inhibition is not fully understood, but prefrontal areas have been repeatedly implicated across task types. For example, inhibition deficits have been implicated in prefrontal lobe damage in both human and animal models (e.g., Butters, Butters, Rosen, \& Stein, 1973; Grafman, 1995; Iverson \& Mishkin, 1970) and in frontal lobe-associated clinical syndromes such as attention-deficit/hyperactivity disorder (Barkley, 1997), Tourette's syndrome (Peterson et al., 1998), and obsessive-compulsive disorder (Enright \& Beech, 1993). Furthermore, neuroimaging and neuropsychological studies implicate prefrontal lobe function in inhibitory control. For example, neuroimaging studies of response inhibition have revealed cerebral activation most consistently in ventral and dorsal prefrontal areas, particularly in the right hemisphere (e.g., Casey, Castellanos, et al., 1997; Casey, Trainor, et al., 1997; Garavan, Ross, \& Stein, 1999; Humberstone et al., 1997; Jonides, Smith, Marshuetz, Koeppe, \& Reuter-Lorenz, 1998; Kawashima et al., 1996; Konishi, Nakajima, Uchida, Kameyama, et al., 1998; Konishi, Nakajima, Uchida, Sekihara, \& Miyashita, 1998; Konishi et al., 1999; Smith, Jonides, Marshuetz, \& Koeppe, 1998; Tsujimoto et al., 1997).

Psychology and Aging, Vol 17, No. 1 (March 2002): pg. 56-71. DOI. This article is @ American Psychological Association and permission has been granted for this version to appear in e-Publications@Marquette. American Psychological Association does not grant permission for this article to be further copied/distributed or hosted elsewhere without the express permission from American Psychological Association. 
Many of the cognitive deficits that older adults exhibit are associated with the frontal lobes (e.g., McDowd \& Oseas-Kreger, 1991; Parkin \& Walter, 1992). Consistent with these findings, aging is associated with cortical volume losses that are particularly notable in the frontal cortices (cf. Kemper, 1994; Madden \& Hoffman, 1997; Raz, 2000; Raz et al., 1997). Indeed, some theories focus exclusively on frontal lobe changes to explain age-related cognitive decline (e.g., Arbuckle \& Gold, 1993; Kramer, Humphrey, Latish, Logan, \& Strayer, 1994; Moscovitch \& Winocur, 1995; West, 1996).

Neuroimaging techniques could be very useful in clarifying and explaining age-related effects on cognition, but this literature is very small at present, and the findings across studies are rather inconsistent. These inconsistencies probably result from methodological (e.g., task) differences across studies. However, agerelated activation differences have been found in positron emission computed tomography (PET) studies of perceptual and memory tasks. Frequently, these studies were characterized by decreased activation in elders in some regions relative to young adults, which was often accompanied by increased activation in other, sometimes contralateral, areas (e.g., Backman et al., 1997; Cabeza, Anderson, Houle, Mangels, \& Nyberg, 2000; Cabeza et al., 1997; Grady et al., 1995, 1998; Madden et al., 1999; Nagahama et al., 1997; ReuterLorenz et al., 2000).

Increased activation in elders has typically been associated with compensation. One view, the recruitment hypothesis, posits that diffuse neuron loss in aging is associated with transient (i.e., taskdemand associated) use of additional circuits to aid performance (e.g., Cabeza et al., 1997). For example, several studies showed more bilateral activation, particularly in the frontal lobes, during episodic memory retrieval and working memory in older adults, which has been attributed to homologous areas that are recruited to assist in task performance (e.g., Backman et al., 1997; Cabeza et al., 1997; Madden et al., 1999; Reuter-Lorenz et al., 2000). Another view, reorganization, posits that neural decline in aging prompts the consistent use of alternative brain circuitry as a means of compensation for failing circuitry (e.g., Della-Maggiore et al., 2000; Grady, 1998). Evidence included decreased activation in one nonfrontal region that was accompanied by increased activation in a

Psychology and Aging, Vol 17, No. 1 (March 2002): pg. 56-71. DOI. This article is @ American Psychological Association and permission has been granted for this version to appear in e-Publications@Marquette. American Psychological Association does not grant permission for this article to be further copied/distributed or hosted elsewhere without the express permission from American Psychological Association. 
prefrontal area (e.g., Grady et al., 1994). More important, recruitment and reorganization may be less distinguishable than a discussion of them as separate "views" implies. That is, "recruited" and "alternative" circuits might be indistinguishable depending on the analytic technique used, and in some cases they might be one and the same because they both can reflect compensatory activity.

One important difficulty for neuroimaging studies of clinical or special populations is the potential confounding of performance differences with activation differences. Indeed, this potential confound complicates interpretation of previous aging-neuroimaging studies and may contribute to inconsistencies in results among them. The advent of event-related procedures, however, can substantially reduce this difficulty by allowing the removal of error-based contributions to functional maps. That is, activation responses collected during error trials may be quite different than those collected during correct trials, the inclusion of which can effectively increase "noise" relative to "signal" in analysis. The removal of error trials reduces noise, thereby effectively enhancing signal. Thus, although a task may be inherently more demanding or difficult for one group compared with another, actual performance differences can be removed and activation can be compared only during performance successes so that the groups are better equated.

The purpose of this study was to use the specificity and spatial and temporal resolution afforded by event-related fMRI to evaluate the functional neuroanatomy of inhibitory control in adults ranging from young to elderly, with performance factors controlled. The article is presented in two parts, with analysis of all participants (aged 18 to 78 years) in Part 1 to examine age effects and analysis of just a subset of older participants in Part 2 to separately examine age and performance factors.

\section{Part 1: Participants Aged 18 to 78}

A response inhibition, or conditional go/no-go, task developed for use with fMRI (Garavan et al., 1999) was used to evaluate the functional neuroanatomy of inhibitory control in four age-associated groups of healthy, well-educated adults. Based on the cognitive aging

Psychology and Aging, Vol 17, No. 1 (March 2002): pg. 56-71. DOI. This article is (c) American Psychological Association and permission has been granted for this version to appear in e-Publications@Marquette. American Psychological Association does not grant permission for this article to be further copied/distributed or hosted elsewhere without the express permission from American Psychological Association. 
literature, slower and less accurate performance on the task was expected in older relative to younger groups (cf. McDowd et al., 1995). In addition, all groups were expected to demonstrate predominantly right hemisphere prefrontal and parietal activation during successful inhibitions ("no-go"; e.g., Garavan et al., 1999; Konishi, Nakajima, Uchida, Kameyama, et al., 1998; Konishi et al., 1999), and older groups were expected to exhibit additional diffuse activation, particularly in prefrontal regions (e.g., Cabeza et al., 1997; Grady et al., 1994; Madden et al., 1997). Thus, the results were expected to support the recruitment hypothesis. Finally, it was predicted that response to targets ("go") would elicit activation areas that are distinct from those for no-go stimuli, predominantly in motor and premotor regions, with relatively comparable activation in the age groups (because there was no basis for prediction of specific differences).

\section{Method}

\section{Participants}

Thirty-four participants who spanned the adult age range (1878 years; 20 women, 14 men) participated in this experiment. Participants were recruited from local colleges and universities, through newspaper advertisements, and from a university retirees group. Some participants were paid $\$ 10$ per hour for their participation in the study. All participants were predominantly right handed; they were free of medications, alcohol, drugs, and medical conditions that could impact on performance or functional imaging; they fasted (except water) for at least $2 \mathrm{hr}$ prior to imaging; and they were free of significant history of or present neurological and psychological conditions. Visual acuity was corrected, as necessary, to match to prescription lenses, or to at least 20/40. Participants aged 50 and over were screened with the Mini-Mental State Exam (MMSE; scores above 26, $M=28.6, S D=1.5$; Folstein, Folstein, \& McHugh, 1975) and the Geriatric Depression Scale (scores below 10, $M=2.9, \mathrm{SD}=3.1$; Sheikh \& Yesavage, 1986).

Participants were divided into four groups based on age: a young adult group (18-31 years, $M=25.5 ; 4$ women, 6 men), a middle adult group (33-55 years, $M=43.3 ; 4$ women, 3 men), a 
young elderly group ( $62-72$ years, $M=68.9 ; 8$ women, 1 man), and an elderly group (73-78 years, $\mathrm{M}=75.1 ; 4$ women, 4 men). The groups differed significantly in number of years of education, with education increasing with age, $F(3,30)=5.54, \mathrm{p} \leq .004$; mean $( \pm$ SD) $=15.5$ (1.8), 17.1 (2.0), 16.9 (2.2), 19.3 (1.8) for young, middle adult, young elderly, and elderly, respectively. Post hoc analysis determined that the elderly group had significantly more education than did each of the other three groups (Tukey's honestly significant difference [HSD], $\mathrm{p} \leq .05$ ). Recruitment from a university-affiliated retirement group was done to better equate young with old in education, although somewhat the opposite extreme was achieved. However, this was expected to have little impact on the study because declines in older adults could be confounded with a lack of education but not confounded with advanced education.

\section{Materials}

The response inhibition task (see Figure 1) has been used previously as a measure of motoric inhibition for event-related fMRI (Garavan et al., 1999). A stream of letters was presented serially at 500-ms intervals with an interstimulus interval of $0 \mathrm{~ms}$. Participants were required to press a button whenever specific letters ( $\mathrm{X}$ or $\mathrm{Y}$ ) were presented. Following two training and practice runs with 75 targets (i.e., for practice and to develop a prepotent response to the targets), a second rule was added that stipulated response only to alternating target letters (e.g., $X, Y, X$ ), thereby requiring inhibition of response to repeated target letters (e.g., $X, X)$. For example, if the last letter to which a participant made a response was an $X$, then a response was only to be made to a $Y$, inhibiting a response to any Xs ("lures") that occurred in the interim. This differs somewhat from standard go/no-go tasks in that there is no consistent stimulus- response mapping (e.g., green $=$ go, red = no-go), but as such, the current task maximizes response prepotency. In addition, although there is a working memory component to the task (i.e., "1-back"), there is no need to update working memory during lure presentation, thereby separating the working memory load and response inhibition components of the task.

Psychology and Aging, Vol 17, No. 1 (March 2002): pg. 56-71. DOI. This article is (c) American Psychological Association and permission has been granted for this version to appear in e-Publications@Marquette. American Psychological Association does not grant permission for this article to be further copied/distributed or hosted elsewhere without the express permission from American Psychological Association. 


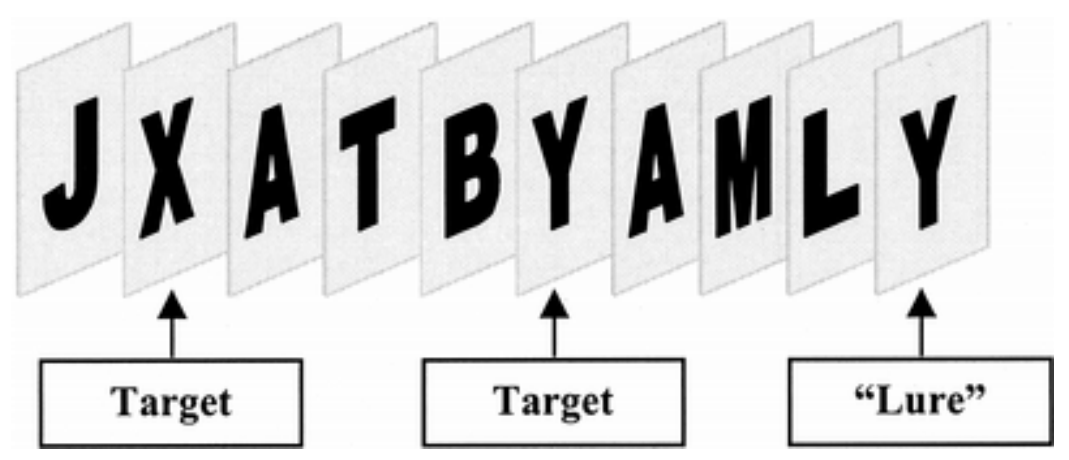

Figure 1. Response inhibition task. Letters were presented serially in black on a white background, one every $500 \mathrm{~ms}$ with 0 -ms interstimulus interval. The task required participants to respond with a button press to the target letters $X$ and $Y$ in alternation. Nonalternating presentations of the letter $X$ or $Y$ (i.e., "lure") required withholding, or inhibiting, a response

One practice run with lures occurred prior to scanning. (Some older participants elected to do two practice runs.) Inhibiting responses to these lures was required on average every $20 \mathrm{~s}$. Valid targets were presented on average every 3.5 s. A minimum of 30 letters (15 s) were presented between lures. During imaging, participants completed four runs ( 250 letters in each) that contained a total of 150 correct targets and 25 lures (of 1,000 total letters). The proportion of correct targets (six times as many targets as lures) was designed to be relatively high to maintain the prepotency of the response to the target letters.

\section{Imaging parameters}

Functional and anatomical brain imaging was conducted using a 1.5T GE Signa scanner equipped with a 30.5-cm i.d. 3-axis local gradient coil and an endcapped quadrature birdcage radio-frequency head-coil (Wong, Buskamp, \& Hyde, 1992). Anatomic images (highresolution spoiled GRASS) were acquired prior to functional imaging to enable subsequent anatomical localization of functional activation. Contiguous 7-mm sagittal slices that covered the entire brain were collected using a blipped gradient echo, echo-planar pulse sequence $(\mathrm{TE}=40 \mathrm{~ms} ; \mathrm{TR}=2000 ; \mathrm{FOV}=24 \mathrm{~cm} ; 64 \times 64$ matrix; $3.75 \times 3.75$ in-plane resolution). Soft foam padding was used to limit head movements, and earplugs were used for hearing protection. Prism 
glasses (with correction, as necessary) were used to view the task, which was back projected on a screen at the participant's feet.

\section{Analyses of fMRI data}

All data processing was conducted with the software package AFNI (Cox, 1996). In-plane motion correction and edge detection algorithms were applied first to correct for minor head movements. The fMRI images were then viewed cinematically (i.e., rapidly in series) to detect and then remove participants with uncorrectable head movements. Trials in which participants were unsuccessful in detecting targets or inhibiting a response to lures were omitted from further analysis.

A deconvolution procedure was used to separately identify lure and target waveforms. Importantly, event-related designs do not require a separate control condition as a "baseline" because baseline can be computed based on the portion(s) of the entire time-series where there is an absolute absence of events, the remainder of the time series being considered baseline plus the events or parts of the events. The deconvolution model includes both intercept and slope parameters, whereby the intercept parameter represents the baseline component of the time series. The individual impulse-response functions that are derived for the deconvolution were each modeled using a nonlinear regression (NLR) procedure (Ward et al., 1998). Each voxel was modeled with the gamma-variate function, $y=k(t-$ to $)^{r} e^{-(t-t 0) / b} u(t-t 0)$, where $u$ is the step function such that

$$
u\left(t-t_{0}\right)= \begin{cases}0, & \text { if } t \leq t_{0} \\ 1, & \text { if } t>t_{0}\end{cases}
$$

This function has been shown to be a good model of the hemodynamic response (Aguirre, Zarahn, \& D'Esposito, 1998; M. Cohen, 1997). The model parameters $k, r, b$, and to were allowed to vary around those found by $\mathrm{M}$. Cohen (1997), and the onset times were constrained to occur within $4 \mathrm{~s}$ of lure events, to allow for the large inter- and intrasubject variability of the hemodynamic response (Aguirre et al., 1998). For the NLR procedure, 1,000 random starting values of the model parameters were chosen within their respective ranges. For the

Psychology and Aging, Vol 17, No. 1 (March 2002): pg. 56-71. DOI. This article is (c) American Psychological Association and permission has been granted for this version to appear in e-Publications@Marquette. American Psychological Association does not grant permission for this article to be further copied/distributed or hosted elsewhere without the express permission from American Psychological Association. 
10 starting vectors with the smallest sum-squares error (SSE), the values of the parameters were optimized using the simplex algorithm, with the resulting fit with the minimum SSE kept. From this fit, the area under the curve was calculated and, expressed as a percentage of the area under the baseline, was used in subsequent statistical analyses.

The NLR procedure thus achieved the best-fitting function for each voxel time-series within the parameters of a typical hemodynamic waveform. This general procedure has been used successfully in an event-related study with a gamma-variate model (Garavan et al., 1999) and in an emotion study that was using a betavariate model (Garavan et al., 2000). The use of this technique is also supported by our recent finding of no differences in the model parameters between young and older adults with this task (except in regional magnitudes; Nielson, Garavan, Langenecker, Stein, \& Rao, 2001), which is consistent with the findings of D'Esposito, Zarahn, Aguirre, and Rypma (1999). The area under the fit was converted to a percentage area-under-the-curve (\%AUC) using the baseline from the deconvolution. The \%AUC maps were converted to the standard stereotaxic coordinate system of Talairach and Tournoux (1988). I mages were spatially blurred using a 4.2-mm full-width-at-halfmaximum isotropic Gaussian filter.

For lure and target analyses, one-sample t tests were performed for each separate participant group, on a voxel-by-voxel basis, using \%AUC. A Monte Carlo randomization procedure was used to identify the probability of obtaining erroneous activation clusters. This procedure generates voxels at a rate equal to the significance criterion specified, proportional to the total number of voxels in the dataset, and calculates a cluster size that corresponds to the true false-positive rate for these conditions. Using 1,000 iterations, a false positive cluster probability of .001 was achieved with a minimum cluster size of $109 \mathrm{~mm}^{3}$. This statistical threshold, for example, $\mathrm{t}(8)=5.04, \mathrm{p}$ $\leq .001$, in combination with the $109-\mathrm{mm}^{3}$ minimum cluster criterion, was then applied to all voxels in the real data. The advantages of combining a voxel-based threshold with a minimum cluster size have been described elsewhere (e.g., Forman et al., 1995; Ward et al., 1998). When the results of this procedure were viewed, a single, extremely large left motor cortex cluster that was associated with the

Psychology and Aging, Vol 17, No. 1 (March 2002): pg. 56-71. DOI. This article is @ American Psychological Association and permission has been granted for this version to appear in e-Publications@Marquette. American Psychological Association does not grant permission for this article to be further copied/distributed or hosted elsewhere without the express permission from American Psychological Association. 
target response analysis resulted, which encompassed much of the precentral and postcentral gyri. Presumably, this activation reflects the target motor response, and its large size reflects the greater power of this analysis than the analysis for lures (i.e., there were six times as many targets as lures within the time-series). As such, a more stringent threshold ( $t=6.62, p \leq .0003$ ) was applied to the target data to better detect distinct clusters of activation in different anatomical locations.

Significantly, active areas for each of the four age groups were combined, separately for targets and lures, such that all significant clusters, from any group, were used as regions of interest (ROI). Each participant's average \% AUC in each ROI cluster was determined. These \%AUC values were then used in separate analysis of variance (ANOVA) procedures, with a $p \leq .01$ threshold for significance, to determine differences among the four age groups.

\section{Behavioral analyses}

An ANOVA was used to evaluate group differences in percentage of correct successful inhibitions, percentage of correct valid target responses (correct response within 1 s of target presentation), and averaged response times to targets. Correlations were computed between behavioral performance indices and average cluster \%AUC values as confirmatory, post hoc analyses. As such, no correction factor was used; these analyses were held to a significance criterion of $p \leq .05$.

\section{Results}

\section{Behavioral analyses}

Group statistics for performance on the response inhibition task are presented in Table 1. There was a significant difference among the groups in reaction time, $\mathrm{F}(3,30)=3.01$, $\mathrm{p} \leq .045$, where post hoc analysis revealed that the elderly group was significantly slower than was the young group (Tukey's HSD, $p \leq .01$; all others, $p \geq .08$ ). There was no significant effect of group on percentage of correct targets, $F(3,30)=2.1, p \geq .13$, or percentage of successful 
inhibitions, $F(3,30)=2.27, p \geq .10$. Although the groups did not significantly differ in inhibitory performance, a trend toward decline with age was evident (see Table 1). A correlational analysis confirmed this, revealing a negative relationship between percentage of correct inhibitions and age $(r=-.435, p \leq .01)$. Furthermore, it was notable that only in participants over the age of 50 was inhibitory performance $\leq 80 \%$ correct ( $\leq 80 \%$ correct in young: 0 of 10 ; middle adult: 2 of 7 ; young elderly: 5 of 9; elderly: 4 of 8 ). Overall, the scores ranged from $28 \%$ correct inhibitions ( 7 of 25 trials; 2 participants, 1 each in the middle adult and elderly groups) to $100 \%$ correct.

Table 1

Descriptive Statistics for the Response Inhibition Task in Each Group

\begin{tabular}{|c|c|c|c|c|c|c|c|c|}
\hline \multirow[b]{2}{*}{ Variable } & \multicolumn{2}{|c|}{$\begin{array}{c}\text { Young } \\
\text { (aged 18-31) }\end{array}$} & \multicolumn{2}{|c|}{$\begin{array}{l}\text { Middle adults } \\
\text { (aged 33-55) }\end{array}$} & \multicolumn{2}{|c|}{$\begin{array}{l}\text { Young elderly } \\
\text { (aged 62-72) }\end{array}$} & \multicolumn{2}{|c|}{$\begin{array}{c}\text { Elderly } \\
\text { (aged 73-78) }\end{array}$} \\
\hline & $M$ & $S D$ & $M$ & $S D$ & $M$ & $S D$ & $M$ & $S D$ \\
\hline$\%$ correct inhibitions & 92.8 & 3.7 & 80.6 & 24.3 & 80.9 & 10.5 & 72.0 & 24.6 \\
\hline$\%$ correct targets & 99.3 & 0.9 & 98.3 & 2.3 & 97.7 & 1.9 & 97.6 & 1.4 \\
\hline Reaction time (ms) & 456.8 & 39.4 & 482.3 & 62.3 & 498.6 & 67.7 & 536.5 & 57.9 \\
\hline
\end{tabular}

Descriptive Statistics for the Response Inhibition Task in Each Group

\section{Functional activation to response inhibition (lures)}

In each participant group, activation during successful inhibition involved a distributed network of regions that was comparable to what has been described previously for young adults (e.g., Garavan et al., 1999). Right prefrontal and parietal regions were most common in each group, as well as left frontal regions in some groups. Forty-three clusters, all those that met criteria for significant activation in at least one group, were compared between-groups (see Table 2). Significant group differences were found in the left middle and inferior gyri, presupplementary motor area (pre-SMA), left putamen, bilateral caudate, thalamus, right middle frontal gyrus, and right fusiform gyrus. Post hoc analyses revealed two clusters, in the right middle frontal and fusiform gyri, which were more active in the young group than in others. Several striatal-thalamic clusters were significantly less active in the middle adult group relative to other groups. However, most of the significant differences were attributable to greater activation in the elderly group relative to other groups, particularly in one right middle frontal gyrus cluster and in multiple left frontal

Psychology and Aging, Vol 17, No. 1 (March 2002): pg. 56-71. DOl. This article is (C) American Psychological Association and permission has been granted for this version to appear in e-Publications@Marquette. American Psychological Association does not grant permission for this article to be further copied/distributed or hosted elsewhere without the express permission from American Psychological Association. 
NOT THE PUBLISHED VERSION; this is the author's final, peer-reviewed manuscript. The published version may be accessed by following the link in the citation at the bottom of the page.

\section{clusters (see Figure 2a).}

Table 2

Clusters of Significant Activation Associated With Response Inhibition (No-Go) in Any of the Four Participant Groups, With Between-Groups Analysis Results

\begin{tabular}{|c|c|c|c|c|c|c|c|c|c|}
\hline & Location and lobe & BA & Vol. $\left(\mathrm{mm}^{3}\right)$ & $\mathrm{x}$ & $\mathrm{Y}$ & $\mathrm{Z}$ & $F$ & $p$ & Result \\
\hline \multicolumn{10}{|c|}{ Right hemisphere } \\
\hline \multirow[t]{14}{*}{ Frontal } & Middle frontal gyrus & 9 & 1028 & 36 & 30 & 36 & 3.85 & .019 & \\
\hline & & $9 / 8$ & 354 & 35 & 20 & 38 & 2.11 & .120 & \\
\hline & & $8 / 6$ & 127 & 24 & 16 & 48 & 1.99 & .136 & \\
\hline & & 6 & 298 & 30 & -4 & 54 & 1.25 & .305 & \\
\hline & & 6 & 191 & 26 & 15 & 54 & 6.15 & .002 & $\mathrm{E}>$ all \\
\hline & $\dagger$ & 6 & 116 & 19 & 14 & 56 & 2.4 & .088 & \\
\hline & & 6 & 144 & 31 & -8 & 41 & 2.07 & .125 & \\
\hline & & 6 & 137 & 45 & 4 & 34 & 1.17 & .334 & \\
\hline & & 10 & 139 & 36 & 46 & 17 & 1.8 & .168 & \\
\hline & & $10 / 46$ & 415 & 46 & 39 & 14 & 1.41 & .259 & \\
\hline & Inferior frontal gyrus & $46 / 9 / 44$ & 202 & 37 & 26 & 15 & 8.23 & .0001 & $\mathrm{Y}>$ all \\
\hline & & $45 / 46$ & 109 & 41 & 17 & 21 & 0.79 & .507 & \\
\hline & Medial frontal gyrust & 6 & 113 & 3 & 1 & 54 & 1.37 & .271 & \\
\hline & Insula & 13 & 531 & 35 & 15 & 2 & 3.18 & .038 & \\
\hline \multirow[t]{6}{*}{ Parietal } & Inferior parietal lobule & 40 & 952 & 51 & -43 & 39 & 2.9 & .051 & \\
\hline & $\S$ & 40 & 118 & 39 & -55 & 45 & 1.07 & .377 & \\
\hline & & 43 & 110 & 54 & -11 & 14 & 3.74 & .021 & \\
\hline & Precuneus§ & 19 & 141 & 33 & -63 & 37 & 0.91 & .445 & \\
\hline & Angular gyrus & 39 & 168 & 48 & -61 & 22 & 2.07 & .125 & \\
\hline & Supramarginal gyrus & 40 & 149 & 47 & -50 & 22 & 1.16 & .339 & \\
\hline \multirow[t]{2}{*}{ Occipital } & Fusiform gyrus & 37 & 137 & 38 & $-50-$ & -11 & 5.09 & .006 & $\mathbf{Y}>\mathbf{M}, \mathbf{Y E}$ \\
\hline & Inferior occipital gyrus & 18 & 112 & 31 & -83 & -5 & 0.75 & .527 & \\
\hline \multirow[t]{3}{*}{ Subcortical } & Caudate tail & & 163 & 19 & -40 & 19 & 11.7 & .0001 & All $>$ M \\
\hline & Pulvinar & & 146 & 1 & -30 & 9 & 8.46 & .004 & All $>$ M \\
\hline & Caudate head & & 109 & 23 & 7 & 23 & 7.65 & .001 & All $>$ M \\
\hline \multicolumn{10}{|c|}{ Left hemisphere } \\
\hline \multirow[t]{9}{*}{ Frontal } & Middle frontal gyrus & $6 / 9$ & 1153 & -43 & 2 & 38 & 13.11 & .0001 & $\mathbf{E}>\mathbf{M}$ \\
\hline & & 6 & 135 & -24 & -9 & 54 & 4.29 & .012 & $\begin{array}{c}\mathrm{E}>\mathrm{M}, \mathrm{YE} \\
\mathrm{Y}>\mathrm{M}\end{array}$ \\
\hline & Inferior frontal gyrus§ & 44 & 119 & -48 & 9 & 7 & 4.95 & .007 & $\mathbf{E}>\mathbf{Y}, \mathbf{M}$ \\
\hline & & 45 & 258 & -40 & 38 & 3 & 5.64 & .003 & $\mathrm{E}>\mathrm{Y}, \mathrm{YE}$ \\
\hline & & $45 / 46$ & 142 & -46 & 19 & 15 & 4.07 & .015 & \\
\hline & Superior frontal gyrus & 6 & 613 & -16 & 1 & 52 & 2.93 & .049 & \\
\hline & & 8 & 115 & -4 & 36 & 40 & 2.68 & .064 & \\
\hline & Precentral gyrus & $4 / 6$ & 122 & -41 & -17 & 44 & 4.48 & .010 & $\mathbf{E}>\mathbf{Y}, \mathbf{M}$ \\
\hline & Insula & 13 & 132 & -37 & -36 & 20 & 7.67 & .001 & $\mathbf{E}, \mathbf{Y}>\mathbf{M}$ \\
\hline Limbic & Cingulate (bilateral) & $32 / 24 / 6$ & 835 & -2 & 15 & 42 & 1.55 & .221 & \\
\hline \multirow[t]{2}{*}{ Parietal } & $\begin{array}{l}\text { Supramarginal gyrus } \\
\text { Inferior parietal lobule }\end{array}$ & $39 / 40$ & 2062 & -42 & -51 & 34 & 4.34 & .012 & E $>$ all \\
\hline & Superior Parietal lobule & 7 & 154 & -34 & -63 & 47 & 3.01 & .045 & \\
\hline \multirow[t]{5}{*}{ Subcortical } & Caudate & & 308 & -25 & 0 & 22 & 18.8 & .0001 & All $>$ M \\
\hline & Caudate body & & 240 & -20 & -22 & 24 & 4.07 & .015 & \\
\hline & Caudate body & & 157 & -11 & -9 & 23 & 8.46 & .0001 & All $>$ M \\
\hline & Nonspecific (white matter) & & 145 & -22 & -2 & 34 & 5.42 & .004 & YE, E $>$ M \\
\hline & Putamen & & 131 & -26 & 13 & 9 & 6.63 & .001 & $\mathbf{E}>\mathbf{M}$ \\
\hline Cerebellum & Anterior lobe & 122 & -6 & -60 & -1 & 1.9 & 0.151 & & \\
\hline
\end{tabular}

Note. $\quad \mathrm{BA}=$ Brodmann area; $\mathrm{Y}=$ young: $\mathrm{M}=$ middle adult; $\mathrm{YE}=$ young elderly; $\mathrm{E}=$ elderly; coordinates are in $\mathrm{mm}$ from the anterior commissure (Talairach \& Tournoux, 1988) with positive = right $(\mathrm{X})$, anterior $(\mathrm{Y})$, and superior (Z); differences that are significant $(p \leq .01)$ are in bold; $\dagger=$ includes part of presupplementary motor area; $\$=$ cluster correlated with performance variables (see Results section).

Psychology and Aging, Vol 17, No. 1 (March 2002): pg. 56-71. DOI. This article is (c) American Psychological Association and permission has been granted for this version to appear in e-Publications@Marquette. American Psychological Association does not grant permission for this article to be further copied/distributed or hosted elsewhere without the express permission from American Psychological Association. 
NOT THE PUBLISHED VERSION; this is the author's final, peer-reviewed manuscript. The published version may be accessed by following the link in the citation at the bottom of the page.

Clusters of Significant Activation Associated With Response Inhibition (No-Go) in Any of the Four Participant Groups, With Between-Groups Analysis Results

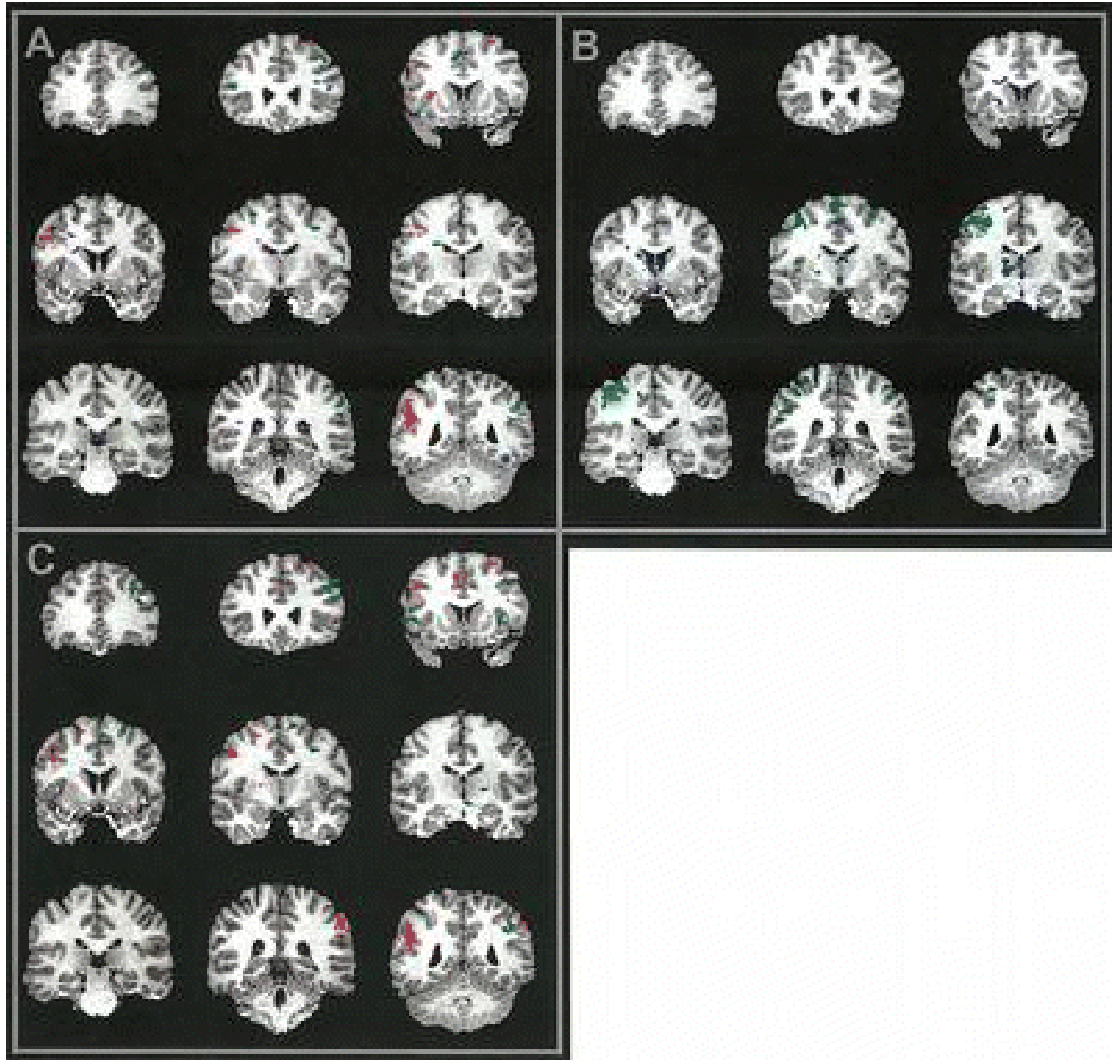

Figure 2. Coronal sections showing similarities and differences in activation in Part 1 among the participant groups during successful inhibition (no-go; a) and response to targets (go; b) and in Part 2 between the two participant groups for successful inhibition (c). The coloration shows clusters of significant activation that were equivalent in the groups (green), significantly greater for elderly participants than other groups (red), significantly greater for young than other groups (blue), and significantly reduced (in a) or greater (in b) in middle adults than other groups (violet). Sections are in standard radiological orientation (i.e., right is left) and are 10 $\mathrm{mm}$ apart beginning at $32 \mathrm{~mm}$ anterior (relative to the anterior commissure) in Panels (a) and (c) and $24 \mathrm{~mm}$ anterior in panel (b)

Pearson correlations of lure cluster activation (\% AUC) with task performance variables revealed associations between right parietal activation and better inhibition performance (clusters denoted by

Psychology and Aging, Vol 17, No. 1 (March 2002): pg. 56-71. DOI. This article is @ American Psychological Association and permission has been granted for this version to appear in e-Publications@Marquette. American Psychological Association does not grant permission for this article to be further copied/distributed or hosted elsewhere without the express permission from American Psychological Association. 
Brodmann area here are also indicated in Table 2 by $\S$; rarea 19 $=.439, \mathrm{p} \leq .009 ;$ rarea40 $=.378, \mathrm{p} \leq .03)$ as well as better target performance (rarea40 $=.607, \mathrm{p} \leq .001$ ) and faster target reaction time (rarea40 $=-.437, \mathrm{p} \leq .01)$. Increased activation in left middle frontal gyrus, which was greater in older than in younger participants, was associated with slowed reaction time to targets, rarea44 $=.479, \mathrm{p}$ $\leq .004$.

\section{Functional activation to target response}

In each participant group, activation during response to targets involved a distributed network of motor regions. Left frontal (e.g., precentral gyrus and SMA proper), parietal, and basal ganglia regions (note that participants were right handed) were apparent in each group. It is notable that a different threshold for activation clusters was used for the target data than for the lure data to see more specific regional activation in response to targets (see Method). This change in threshold did not alter the functional map. That is, it provided more discrete regional activation clusters than it provided with the original threshold, which provided a single, large cluster encompassing most of the left precentral and postcentral gyri. More anterior frontal activation was not found using either threshold. Table 3 displays the clusters that were significantly active in at least one group as well as the betweengroups analysis results. The young group exhibited greater activation than did the older groups, predominantly in basal ganglia and thalamic regions, as well as in the right cingulate and left fusiform areas (see Figure $2 \mathrm{~b}$ ). There was also a trend toward greater activation in left precentral gyrus in the young (see Table 3 ). 
NOT THE PUBLISHED VERSION; this is the author's final, peer-reviewed manuscript. The published version may be accessed by following the link in the citation at the bottom of the page.

Table 3

Clusters of Significant Activation Associated With Target Response (Go) in Any of the Four Participant Groups, With Between-Group Analysis Results

\begin{tabular}{|c|c|c|c|c|c|c|c|c|c|}
\hline \multicolumn{2}{|r|}{ Location and lobe } & BA & Vol. $\left(\mathrm{mm}^{3}\right)$ & $\mathrm{x}$ & $\mathrm{Y}$ & $\mathrm{Z}$ & $F$ & $p$ & Result \\
\hline \multicolumn{10}{|c|}{ Right hemisphere } \\
\hline \multirow[t]{3}{*}{ Frontal } & Precentral gyrus & $4 / 6$ & 462 & 29 & -7 & 53 & 0.19 & .901 & \\
\hline & & 4 & 115 & 29 & -21 & 60 & 1.91 & .15 & \\
\hline & Insula & 13 & 158 & 37 & -5 & 9 & 2.00 & .135 & \\
\hline Limbic & Cingulate (bilateral) & $24 / 32 / 6$ & 283 & 1 & -8 & 46 & 4.65 & .009 & $\mathbf{Y}>\mathbf{Y E}$ \\
\hline Parietal & Inferior parietal lobule & 40 & 127 & 41 & -39 & 44 & 3.39 & .03 & \\
\hline \multirow[t]{2}{*}{ Cerebellum } & Anterior lobe & & 121 & 23 & -47 & -2 & 2.54 & .075 & \\
\hline & & Let & hemisphere & & & & & & \\
\hline \multirow[t]{6}{*}{ Frontal } & Precentral gyrus & 4 & 8016 & -36 & -23 & 48 & 4.10 & .015 & \\
\hline & & 4 & 139 & -9 & -36 & 64 & 2.07 & .125 & \\
\hline & Medium frontal gyrus & 6 & 722 & -5 & -8 & 60 & 3.02 & .045 & \\
\hline & Superior frontal gyrus & 8 & 115 & -18 & 28 & 46 & 1.70 & .189 & \\
\hline & Inferior frontal gyrus & 44 & 115 & -45 & -2 & 19 & 0.50 & .688 & \\
\hline & Insula & 13 & 228 & -36 & -5 & 9 & 2.44 & .084 & \\
\hline Limbic $\S$ & & $23 / 31$ & 121 & -15 & -27 & 47 & 0.71 & .55 & \\
\hline \multirow[t]{4}{*}{ Parietal } & Inferior parietal lobule & 40 & 356 & -29 & -52 & 44 & 1.31 & .29 & \\
\hline & & 40 & 315 & -50 & -36 & 30 & 3.27 & .035 & \\
\hline & & 40 & 127 & 41 & -39 & 44 & 3.39 & .03 & \\
\hline & Precuneus & 7 & 141 & -22 & -60 & 47 & 3.77 & .021 & \\
\hline \multirow[t]{2}{*}{ Occipital } & Fusiform gyrus§ & 19 & 118 & -43 & -71 & -2 & 1.74 & .181 & \\
\hline & $\S$ & $18 / 19$ & 247 & -25 & -90 & -2 & 6.43 & .002 & $\mathbf{Y}>\mathbf{Y E}, \mathbf{E}$ \\
\hline \multirow[t]{8}{*}{ Subcortical } & Bilateral DMN, basal & & & & & & & & \\
\hline & ganglia, fornix & & 2447 & -6 & -10 & 8 & 6.03 & .002 & $\mathbf{Y}>\mathbf{Y E}, \mathbf{E}$ \\
\hline & Putamen§ & & 429 & -21 & -4 & 6 & 1.88 & .155 & \\
\hline & Caudate§ & & 397 & -16 & -5 & 19 & 7.08 & .001 & $\mathbf{Y}, \mathbf{M}>\mathbf{E}$ \\
\hline & Caudate & & 152 & -24 & 1 & 26 & 5.47 & .004 & $\mathbf{M}>\mathbf{Y E}, \mathbf{E}$ \\
\hline & Caudate & & 131 & -20 & 11 & 20 & 4.47 & .01 & $\mathbf{Y}>\mathrm{YE}, \mathbf{E}$ \\
\hline & Thalamus/midbrain & & 157 & -7 & -24 & -2 & 0.49 & .689 & \\
\hline & Thalamus (VPL) $\S$ & & 128 & -20 & 15 & 7 & 4.52 & .01 & $\mathbf{Y}>\mathbf{E}$ \\
\hline
\end{tabular}

Note, $\quad \mathrm{BA}=$ Brodmann area; $\mathrm{DMN}=$ dorsomedial nucleus of thalamus; $\mathrm{VPL}=$ ventral posterior lateral nucleus; $\mathrm{Y}=$ young; $\mathrm{M}=$ middle adult; $\mathrm{YE}=$ young elderly; $\mathrm{E}=$ elderly; coordinates are in $\mathrm{mm}$ from the anterior commissure (Talairach \& Tournoux, 1988) with positive $=$ right $(\mathrm{X})$, anterior $(\mathrm{Y})$, and superior $(\mathrm{Z})$; differences that are significant $(p<.01)$ are in bold; $\xi=$ cluster correlated with performance variables (see Results section).

Clusters of Significant Activation Associated With Target Response (Go) in Any of the Four Participant Groups, With Between-Group Analysis Results

Target cluster activation (\% AUC) correlations with task performance variables revealed some interesting relationships. Better target performance was associated with increased activation in the left fusiform gyrus $(r=.451, p \leq .007)$ and left caudate, $(r=.459, p$ $\leq .006)$, with a trend also for the left ventral posterior lateral thalamus $(r=.350, p \leq .05)$ and left putamen $(r=.342, p \leq .05)$. Faster reaction time was associated with increased left fusiform $(r=-.452, p$ $\leq .01$ ) and left inferior occiptal/temporal areas (Brodmann area 18/19; $r=-.475, p \leq .004)$, with a trend also with increased left caudate

Psychology and Aging, Vol 17, No. 1 (March 2002): pg. 56-71. DOl. This article is (C) American Psychological Association and permission has been granted for this version to appear in e-Publications@Marquette. American Psychological Association does not grant permission for this article to be further copied/distributed or hosted elsewhere without the express permission from American Psychological Association. 
activation $(r=-.386, p \leq .02)$ and decreased left cingulate activation $(r=.407, p \leq .02)$. The specific clusters bearing these relationships are indicated in Table 3 by $\S$.

\section{Discussion}

The results of Part 1 showed that older participants had generally slower reaction time and poorer inhibition performance than did younger participants. This finding is consistent with some cognitive studies suggesting that inhibitory ability declines with age (see Hasher \& Zacks, 1988; McDowd et al., 1995; Moscovitch \& Winocur, 1995).

As predicted from previous go/no-go task research (e.g., Casey, Castellanos, et al., 1997; Casey, Trainor, et al., 1997; Garavan et al., 1999; Humberstone et al., 1997; Konishi, Nakajima, Uchida, Kameyama, et al., 1998; Konishi, Nakajima, Uchida, Sekihara, et al., 1998; Konishi et al., 1999), functional activation associated with successful inhibition was predominantly right lateralized and focused in prefrontal (e.g., middle and inferior frontal gyri and pre-SMA) and parietal regions. Importantly, activation associated with response to targets was distinguishable from that for inhibition, involving an anticipated motor circuit that included left precentral gyrus and SMA proper, right cerebellum, bilateral parietal, and left basal ganglia and thalamus. These findings are comparable with those described previously with this task (e.g., Garavan et al., 1999). There were only a few between-group differences in target response activation. Younger participants had greater activation than did older groups in some basal ganglia, thalamus, left fusiform, and bilateral cingulate regions. In addition, fast reaction time and accuracy were associated with greater fusiform and basal ganglia activation and with less cingulate activation. It should be mentioned that some researchers have suggested caution in interpretation of age-related activation differences when elders exhibit reduced activation relative to younger adults because of greater intravoxel noise-to-signal ratio (D'Esposito, Zarahn, et al., 1999). However, this potential problem is somewhat minimized by the analysis technique used in this study, which analyzed only correctly performed trials and identified regional (voxel-wise) activation in each group separately prior to any combined analysis. Error trials can decrease the signal-to-noise ratio of an analysis. In

Psychology and Aging, Vol 17, No. 1 (March 2002): pg. 56-71. DOI. This article is (c) American Psychological Association and permission has been granted for this version to appear in e-Publications@Marquette. American Psychological Association does not grant permission for this article to be further copied/distributed or hosted elsewhere without the express permission from American Psychological Association. 
addition, combined analyses in which the activation map is determined on all subjects simultaneously can disadvantage older adults in terms of signal power because young adults, who typically perform better, have more (correct) trials included in the analyses. Although elders may still have lower signal-to-noise ratios than young adults do, the procedures used here at least minimize the sources of the effect.

The pattern of group differences in activation was quite different for inhibition. During successful inhibition, only two regions showed greater activation in the youngest group than in older groups. These were in the right middle frontal gyrus (Brodmann area 46/9) and in the right fusiform gyrus. The right middle frontal gyrus region, along with several of the other clusters, is consistent with an area other researchers have found important in response inhibition and go/no-go tasks (e.g., Garavan et al., 1999; Konishi, Nakajima, Uchida, Sekihara, et al., 1998). Indeed, Casey, Trainor, et al. (1997) reported that when comparing children and adults on inhibitory performance, the middle frontal gyrus was the only region where the volume of activation was significantly correlated with age. They suggested that this area is central to the development of inhibitory ability. Although most of the clusters in right middle frontal gyrus were comparable in activation among the groups, the apparent age-related decrease in this cluster during successful inhibition could be an indicator of functional decline in inhibition.

The right fusiform also had greater activation during inhibition in the young than it had in older groups. Fusiform activation has been observed in other neuroimaging and neurophysiology studies using response inhibition and go/no-go tasks, but little interpretation of it has been given (e.g., Garavan et al., 1999; Kiehl, Kiddle, \& Hopfinger, 2000; Tsujimoto et al., 1997). Fusiform gyrus has been linked with face processing, color perception, expertise, and visual attention (e.g., Allison, McCarthy, Nobre, Puce, \& Belger, 1994). One fMRI study of visuomotor attentional set-shifting, similar to a go/no-go task, reported activation in left middle frontal gyrus, bilateral inferior frontal gyri, and left fusiform gyrus (Omori et al., 1999). The authors suggested that the fusiform activation reflected an attentional demand for visual processing in light of a motor selection rule, which was also required by our task. The results of Omori et al. are similar to ours, which suggests that fusiform activation in our data may reflect visuo-

Psychology and Aging, Vol 17, No. 1 (March 2002): pg. 56-71. DOI. This article is @ American Psychological Association and permission has been granted for this version to appear in e-Publications@Marquette. American Psychological Association does not grant permission for this article to be further copied/distributed or hosted elsewhere without the express permission from American Psychological Association. 
motor attentional demands. Greater activation in this region in young relative to older participants could suggest greater difficulty for elders in meeting this demand.

In contrast to the two regions with greater activation in young, the majority of group differences in inhibition activation involved greater activation in elderly participants relative to others. Most of these regions were in left prefrontal clusters (e.g., Brodmann areas 6, $44,45)$. The increased left prefrontal activation in older adults that has been reported in PET studies of perceptual and memory tasks has been interpreted as compensatory (e.g., Cabeza et al., 1997; Grady et al., 1994; Madden et al., 1997). Our data support such a conclusion. That is, because the older adults have more difficulty with the task, their comparable (and in one case reduced) activation in right prefrontal clusters during successful inhibition is accompanied by the recruitment of left prefrontal regions to complete the task successfully. Indeed, slower reaction time, which might reflect increased difficulty with the task and therefore a greater requirement for functional recruitment, was associated with increased activation in one left prefrontal cluster (Brodmann area 44; Broca's area). This relationship could also be a result of greater use of subvocal rehearsal of the previous target compared with the current target (i.e., lure) in older adults. This finding conflicts with that of Rypma and D'Esposito (2000), who reported a negative association between prefrontal activation and reaction time in elders, and instead is consistent with their results of a positive association in younger adults. The difference might simply reflect task or regional differences, because neither is directly comparable between studies.

The last region with greater elderly activation than in other groups was in Brodmann area 6 in the right hemisphere, a region functionally defined as pre-SMA (e.g., Picard \& Strick, 1996; Vorobiev, Bovoni, Rizzolatti, Metelli, \& Luppino, 1998). As distinct from SMA proper, pre-SMA has been identified as critical for response inhibition (Garavan et al., 1999; Humberstone et al., 1997). Additional evidence of the importance of pre-SMA for response inhibition comes from a person with a bilateral (but primarily right hemisphere) tumor in this region, who had selective, severe inhibitory deficits on a go/no-go task and impaired Trail-Making-B performance until the tumor was removed (Leimkuhler \& Mesulam, 1985). In the present study, there were

Psychology and Aging, Vol 17, No. 1 (March 2002): pg. 56-71. DOI. This article is @ American Psychological Association and permission has been granted for this version to appear in e-Publications@Marquette. American Psychological Association does not grant permission for this article to be further copied/distributed or hosted elsewhere without the express permission from American Psychological Association. 
several regions of activation in both the right and left hemispheres that could be characterized as pre-SMA, with only the one cluster differing between the groups. Similar to the relative increase in left prefrontal activation in elderly participants, their increased right preSMA activation is suggestive of compensation.

There were several group differences in basal ganglia and pulvinar clusters, all of which involved decreased activation in the middle adult group relative to other groups. The reason for this difference is unclear, particularly because this age group is relatively unstudied. Parkinson's disease, which affects the basal ganglia and usually onsets in middle adulthood, could lead to decreased basal ganglia activation, but the participants in the present sample had no indications of degenerative disease. Further study of this finding is warranted.

\section{Part 2: Participants Aged 50 and Over}

Part 1 revealed age-related differences in functional neuroanatomy of response inhibition. I mportantly, inhibition performance on the task did not drop below $80 \%$ until age 50 , and activation differences, also most notable after this age, were characterized by greater left prefrontal activation. Because the experiment was event related and analysis included only successfully inhibited trials, it could be concluded that the group differences were specifically age related rather than performance related. However, because there were older participants who performed quite well on the task, as well as those who performed more poorly (in contrast with younger participants who all performed well), a further analysis that attempted to separate age and performance effects was pursued. The participants aged 50 and over (from Part 1) were organized into two separate age groups. Both groups contained roughly equal numbers of "good" and "poor" performers. The data were reanalyzed based on median split (via age, performance) groupings to determine the relative contributions of age and performance to the functional neuroanatomy of inhibition. The older group was expected to exhibit comparable right prefrontal and parietal activation compared with the younger group as well as to exhibit greater left prefrontal activation

Psychology and Aging, Vol 17, No. 1 (March 2002): pg. 56-71. DOI. This article is @ American Psychological Association and permission has been granted for this version to appear in e-Publications@Marquette. American Psychological Association does not grant permission for this article to be further copied/distributed or hosted elsewhere without the express permission from American Psychological Association. 
NOT THE PUBLISHED VERSION; this is the author's final, peer-reviewed manuscript. The published version may be accessed by following the link in the citation at the bottom of the page.

than younger elders exhibited. There was no firm basis on which to predict the effects of performance group.

\section{Method}

\section{Participants}

Twenty participants from Part 1 (aged 50 to 78 years; 14 women; 6 men) were included in Part 2, by including all from both the elderly and young elderly groups and a median split of those in the middle adult group (i.e., the 3 eldest of 7 ). The participants were subdivided into one of two groups by a median split on age (median $=$ 71.5 years; young-old $=10$ adults aged 50 to 71 years; old-old $=10$ adults aged 72 to 78 years). Table 4 presents the cell sizes and demographic data for these groupings. The young-old group ( 8 women, 2 men) and the old-old group ( 6 women, 4 men) differed in age, $\mathrm{t}(18)=-4.2, \mathrm{p} \leq .001$, but did not differ on the MMSE, $\mathrm{t}(18)$ $=.82, \mathrm{p} \geq .10$, education, $\mathrm{t}(18)=-.89, \mathrm{p} \geq .10$, percentage of correct inhibitions, $\mathrm{t}(18)=-.08, \mathrm{p} \geq .10$, percentage of correct responses to targets, $\mathrm{t}(18)=1.06, \mathrm{p} \geq .10$, or average reaction time to targets, $\mathrm{t}(18)=-.79, \mathrm{p} \geq .10$

Table 4

Group Demographic and Performance Data for Part 2

\begin{tabular}{|c|c|c|c|c|c|c|c|c|c|c|c|c|c|c|c|}
\hline \multirow[b]{2}{*}{ Group } & \multirow[b]{2}{*}{$n$} & \multicolumn{2}{|c|}{ Age } & \multicolumn{2}{|c|}{ Education } & \multicolumn{2}{|c|}{ MMSE } & \multicolumn{2}{|c|}{$\begin{array}{l}\text { Inhibition } \\
\text { accuracy } \\
(\%)\end{array}$} & \multicolumn{2}{|c|}{$\begin{array}{c}\text { Target } \\
\text { accuracy } \\
\text { (\%) }\end{array}$} & \multicolumn{2}{|c|}{$\begin{array}{l}\text { Reaction time } \\
\text { (ms) }\end{array}$} & \multicolumn{2}{|c|}{$\begin{array}{c}\text { Trail-Making } \\
\mathrm{B}-\mathrm{A}(\mathrm{s})\end{array}$} \\
\hline & & $M$ & $S D$ & $M$ & $S D$ & $M$ & $S D$ & $M$ & $S D$ & M & $S D$ & $M$ & $S D$ & $M$ & $S D$ \\
\hline Young-old & 10 & 63.2 & 8.2 & 17.6 & 2.3 & 28.9 & 1.37 & 74.4 & 19.0 & 98.1 & 1.0 & 503.3 & 66.1 & 31.1 & 10.6 \\
\hline Old-old & 10 & 74.5 & 2.1 & 18.5 & 2.2 & 28.3 & 1.64 & 75.6 & 23.0 & 97.3 & 1.9 & 525.6 & 60.1 & 34.8 & 16.2 \\
\hline Young-old/good & 4 & 64.3 & 9.0 & 18.3 & 2.5 & 29.8 & 0.5 & 89.0 & 6.8 & 99.0 & 0.9 & 472.7 & 44.3 & 25.3 & 6.4 \\
\hline Young-old/poor & 6 & 62.5 & 8.4 & 17.2 & 2.3 & 28.3 & 1.5 & 64.7 & 18.3 & 97.4 & 0.5 & 523.8 & 73.7 & 35.5 & 11.9 \\
\hline Old-old/good & 6 & 73.5 & 1.9 & 17.7 & 1.8 & 29.0 & 1.5 & 91.3 & 5.9 & 97.6 & 2.4 & 509.6 & 51.5 & 24.3 & 7.1 \\
\hline Old-old/poor & 4 & 76.0 & 1.4 & 19.8 & 2.5 & 27.3 & 1.3 & 52.0 & 17.0 & 97.0 & 1.2 & 549.5 & 71.7 & 50.5 & 12.6 \\
\hline
\end{tabular}

Note. $\quad$ MMSE $=$ Mini-Mental State Exam.

Group Demographic and Performance Data for Part 2

Whereas task performance was equivalent between groups, within each age group there were those with relatively good and those with relatively poor task performance. As such, the age groups were subdivided for post hoc analyses also by inhibition performance based on a median split of overall inhibition performance. The median score was $78 \%$. Thus, good performers were those with five or fewer errors of commission ( $>78 \%$ correct, $n=10$ ), and poor performers were

Psychology and Aging, Vol 17, No. 1 (March 2002): pg. 56-71. DOI. This article is (c) American Psychological Association and permission has been granted for this version to appear in e-Publications@Marquette. American Psychological Association does not grant permission for this article to be further copied/distributed or hosted elsewhere without the express permission from American Psychological Association. 
those with six or more errors ( $<78 \%$ correct). These distinctions are shown in Table 4 . A factorial ANOVA 2 (age group) $\times 2$ (performance group) showed only a main effect of performance group for percentage of correct inhibitions, $F(1,16)=28.8, p \leq .001$, with no other significant main effects or interactions for any of the behavioral measures, $\mathrm{Fs}(1,16)<2.3$, ps $\geq .15$.

\section{Materials, imaging parameters, and analyses}

Functional and behavioral data for the response inhibition task were obtained during Part 1. Data processing techniques were identical to those that were used in Part 1. Although the fMRI data were obtained during Part 1, the analyses for successful inhibitions were redone for Part 2 based on the two new groups, young-old and old-old. The procedure and statistical thresholds were identical to those used for Part 1 except for the analysis-specific activation threshold value obtained with a new Monte Carlo randomization procedure, $\mathrm{t}(9)=$ $4.50, \mathrm{p} \leq .001$; volume $\geq 109 \mathrm{~mm}^{3}$. Functional comparisons were based on a 2 (age group) $\times 2$ (performance group) ANOVA.

Seventeen of the 20 participants were able to return on a day subsequent to scanning to perform the Trail-Making Test (Forms $A$ and $B$; Lezak, 1995). This is a test of complex visual scanning with a motor speed component, which also involves attention and planning. Because both forms are affected by motor processing speed, Lezak (1995) recommended subtracting test time for Form $A$ from that of Form $B$ to correct for speed, leaving a more pure measure of executive functioning ( $p .382$ ). The group means for these difference scores are shown in Table 4. None of the participants made errors during either Part A or B.

\section{Results and Discussion}

Significantly activated clusters from either group, as well as their group differences, are listed in Table 5. Similar to Part 1, response inhibition elicited a circuit of activation from prefrontal and parietal regions, principally in the right hemisphere but with several left hemisphere clusters as well, to basal ganglia and thalamic regions. Main effect analysis for age group showed that the old-old group demonstrated significantly greater activation than did the young-old

Psychology and Aging, Vol 17, No. 1 (March 2002): pg. 56-71. DOI. This article is (c) American Psychological Association and permission has been granted for this version to appear in e-Publications@Marquette. American Psychological Association does not grant permission for this article to be further copied/distributed or hosted elsewhere without the express permission from American Psychological Association. 
group in 9 of the 27 clusters. These included 2 of 17 right hemisphere clusters (middle frontal gyrus and inferior parietal lobule) and 7 of 10 of the left hemisphere clusters, principally in parietal and prefrontal regions including left pre-SMA, middle and inferior frontal gyri, and the left thalamus (see Figure $2 \mathrm{c}$ ). The young-old group had no clusters with significantly greater activation than the old-old group had. These results amplify those from Part 1 that showed that increased activation in older adults was attributable primarily to the oldest participants. Because the groups were demographically and behaviorally comparable, and the net effect was increased activation during successful inhibition, the results lend credence to the idea that advanced age is associated with the recruitment of additional homologous brain regions to compensate for lost processing efficiency (e.g., Backman et al., 1997; Cabeza et al., 1997; Madden et al., 1999; Reuter-Lorenz et al., 2000). 
NOT THE PUBLISHED VERSION; this is the author's final, peer-reviewed manuscript. The published version may be accessed by following the link in the citation at the bottom of the page.

Table 5

Clusters of Significant Activation Associated With Response Inhibition in Either the Young-Old or Old-Old Groups, With Between-Groups Analysis Results

\begin{tabular}{|c|c|c|c|c|c|c|c|c|c|}
\hline \multicolumn{2}{|c|}{ Location and lobe } & BA & Vol. $\left(\mathrm{mm}^{3}\right)$ & $\mathrm{x}$ & $\mathrm{Y}$ & $\mathrm{Z}$ & $F$ Age & $F$ Perf. & $F \mathrm{AXP}$ \\
\hline \multicolumn{10}{|c|}{ Right hemisphere } \\
\hline \multirow[t]{11}{*}{ Frontal } & Middle frontal gyrus & $46 / 9 / 10 / 45$ & 1727 & 40 & 28 & 28 & 1.7 & 0.8 & 0.2 \\
\hline & & 6 & 719 & 29 & 12 & 51 & $47.2^{*}$ & 2.3 & 6.2 \\
\hline & & 6 & 581 & 27 & -2 & 57 & 0.3 & 0.4 & 0.7 \\
\hline & & 9 & 246 & 39 & 10 & 37 & 3.7 & 1.1 & 0.2 \\
\hline & & 6 & 109 & 29 & -9 & 41 & 1.5 & 0.01 & 0.03 \\
\hline & Inferior frontal gyrus & 45 & 131 & 45 & 39 & 1 & 0.01 & 0.6 & 0.8 \\
\hline & & $44 / 46$ & 112 & 41 & 17 & 22 & 0.2 & 0.7 & 1.3 \\
\hline & Superior frontal gyrus $\hat{t}$ & 6 & 226 & 14 & 16 & 62 & 0.1 & $12.8^{\circ}$ & $7.3^{\circ}$ \\
\hline & Medial frontal gyrust & 6 & 215 & 2 & 0 & 55 & 2.7 & 0.2 & 0.1 \\
\hline & & 6 & 146 & 9 & -9 & 61 & 3.0 & 0.2 & 0.1 \\
\hline & & 25 & 135 & 4 & 19 & -5 & 2.3 & 0.7 & 1.2 \\
\hline \multirow[t]{2}{*}{ Parietal } & Inferior parietal lobule & 40 & 1032 & 51 & -41 & 41 & $11.5^{\circ}$ & 1.1 & 0.3 \\
\hline & & 40 & 398 & 39 & -49 & 36 & 5.2 & 0.0 & 0.04 \\
\hline \multirow[t]{3}{*}{ Temporal } & Superior temporal & & & & & & & & \\
\hline & gyrus & 22 & 321 & 50 & -54 & 27 & 3.2 & 0.0 & 0.1 \\
\hline & Middle temporal gyrus & 21 & 236 & 51 & -34 & -2 & 1.0 & 0.03 & 0.0 \\
\hline \multirow[t]{2}{*}{ Subcortical } & Putamen & & 209 & 32 & 13 & 5 & 3.4 & 1.3 & 2.6 \\
\hline & VLN & & 159 & 17 & -14 & 6 & 1.1 & 0.5 & 5.5 \\
\hline \multicolumn{10}{|c|}{ Left hemisphere } \\
\hline \multirow[t]{6}{*}{ Frontal } & Middle frontal gyrus & 6 & 1036 & -41 & 4 & 37 & $26.2^{\mathrm{s}}$ & 0.1 & 0.0 \\
\hline & & 6 & 116 & -31 & -2 & 54 & $10.7^{\mathrm{s}}$ & 0.01 & 0.0 \\
\hline & Inferior frontal gyrus & $44 / 45$ & 458 & -44 & 10 & 5 & 5.7 & 0.4 & 0.4 \\
\hline & & 44 & 138 & -41 & 8 & 21 & $17.2^{\circ}$ & 0.6 & 1.2 \\
\hline & Superior frontal gyrus & 6 & 425 & -14 & -4 & 54 & $32.0^{\circ}$ & $6.4^{*}$ & 2.7 \\
\hline & & 6 & 154 & -22 & 9 & 48 & 3.0 & 2.1 & 1.0 \\
\hline Limbic & Cingulate (bilateral) $\div$ & $32,24,6$ & 729 & -3 & 15 & 41 & $9.1^{\circ}$ & 0.7 & 0.3 \\
\hline \multirow[t]{2}{*}{ Parietal } & Inferior parietal lobule & 40 & 2548 & -38 & -55 & 37 & $22.8^{\circ}$ & 0.1 & 0.0 \\
\hline & & 40 & 116 & -45 & -34 & 27 & 4.9 & 2.6 & 0.1 \\
\hline Subcortical & VAN & & 187 & -15 & -4 & 11 & $17.0^{*}$ & $7.5^{*}$ & 0.01 \\
\hline
\end{tabular}

Note. $\quad \mathrm{BA}=$ Brodmann area; $\mathrm{VLN}=$ ventral lateral nucleus, thalamus; $\mathrm{VAN}=$ ventral anterior nucleus, thalamus; coordinates are in mm from the anterior commissure (Talairach \& Tournoux, 1988) with positive = right $(\mathrm{X})$, anterior $(\mathrm{Y})$, and superior $(\mathrm{Z})$; $\$$ includes part of presupplementary motor area.

$*=p \leq .01$

Clusters of Significant Activation Associated With Response Inhibition in Either the Young-Old or Old-Old Groups, With Between-Groups Analysis Results

The young-old and old-old groups were comparable in terms of response inhibition performance, but each age group included both good and poor performers (see Table 4). Performance group analyses revealed three main effects of performance: right and left pre-SMA regions and left thalamus. In these areas, poorer performers had greater activation than good performers had. The left pre-SMA region is the same one that had a significant main effect for age. Finally, there was a significant interaction of age and performance group in right pre-SMA, such that poorer performers had greater activation than good performers had for successful inhibitions, but the effect was

Psychology and Aging, Vol 17, No. 1 (March 2002): pg. 56-71. DOI. This article is (c) American Psychological Association and permission has been granted for this version to appear in e-Publications@Marquette. American Psychological Association does not grant permission for this article to be further copied/distributed or hosted elsewhere without the express permission from American Psychological Association. 
greatest in the oldest participants. Figure 3 shows four of the specific effects in detail, with differences attributable to age only in right and left middle frontal gyrus (aFigure $3 a, b \underline{3 b}$, respectively), a difference attributable to both age and performance independently in left preSMA (Figure $3 \mathrm{C}$ ), and the interaction of age and performance in right pre-SMA (Figure $3 d$ ). Thus, age was the primary contributor to activation differences, but inhibition performance also made a specific contribution. In addition, the results support the role of pre-SMA in successful response inhibition and suggest that those who have difficulty with inhibition use pre-SMA (i.e., especially the right) to a greater degree than others and can recruit contralateral pre-SMA (i.e., especially the left) to assist with response inhibition when necessary.
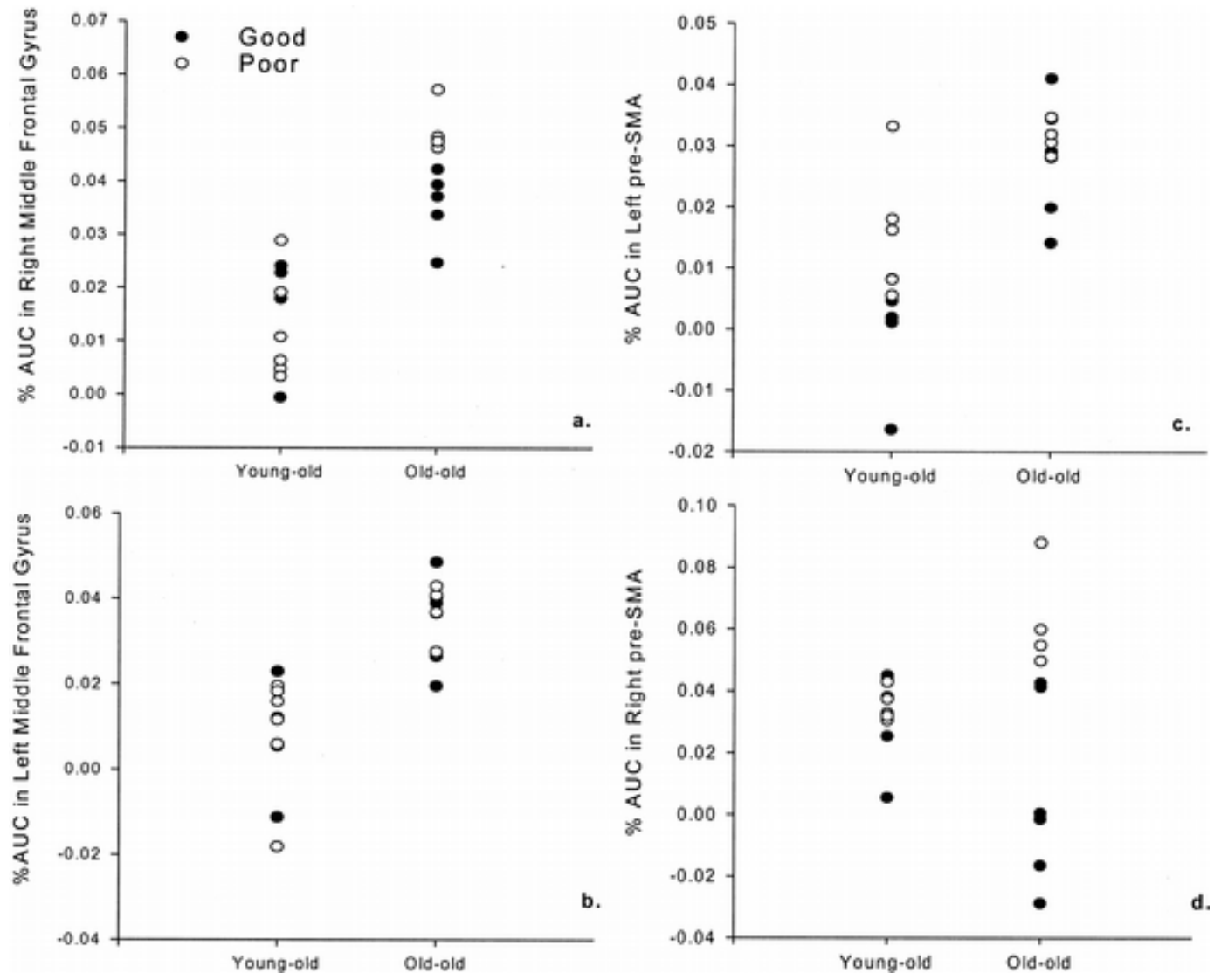

Figure 3. Scatterplots showing regional activation (percentage area-under-the-curve or \%AUC) in individual participants separated by both age group (young-old, old-old) and inhibitory performance group (good, poor). Age but not performance predicted \%AUC in right and left middle frontal gyrus clusters (a) and (b), whereas age and performance predicted \%AUC in left presupplementary motor area or pre-SMA (c). Inhibitory performance only predicted \%AUC in right pre-SMA (d)

The Trail-Making score was examined because it is commonly used as a measure of executive function (cf. Lezak, 1995) and was 
expected to be correlated with response inhibition (e.g., Leimkuhler \& Mesulam, 1985). A factorial ANOVA showed a main effect of inhibition performance group, $F(1,13)=13.95$, $p \leq .002$, with no main effect of age group or interaction of performance and age group $(p>.10)$. Moreover, the Trail-Making test score correlated significantly with inhibitory performance $(r=-.70, p \leq .002)$, suggesting that performance of the two tasks has a common underlying factor. A correlational matrix of the Trail-Making score with \% AUC for the regions that were activated by the response inhibition task yielded one trend: The right pre-SMA region, whose activation interacted with age and inhibition performance, correlated with Trail-Making (pre-SMA; $r$ $=.55, \mathrm{p} \leq .02$ ). The correlation between this cluster and percentage of correct inhibition performance is nearly identical $(r=-.56, p$ $\leq .01)$, and partial correlations that remove the effect of either behavioral task greatly reduces the relationships (rtrail-making $\times$ pre$\mathrm{SMA}($ inhibition $)=.23$, rinhibition $\times$ pre-SMA (trail-making $)=-.35)$. This gives further support to the idea that the two tasks measure comparable abilities and supports the role of pre-SMA in inhibitory control.

\section{General Discussion}

The purpose of this study was to investigate differences in the functional neuroanatomy of inhibitory control in adults from across the life span. As predicted, advanced age was associated with slower response to targets and more errors of commission on a response inhibition task. This result is consistent with many behavioral studies that show that inhibitory control declines with age (cf. McDowd et al., 1995; Moscovitch \& Winocur, 1995). Importantly, the present study employed highly educated, healthy elders, which suggests that inhibitory losses occur even under relatively optimal aging conditions.

Our hypothesis that the members of all age groups would exhibit predominantly right hemisphere activation during inhibition of a prepotent response was supported. Furthermore, the principal regions involved were in right prefrontal and parietal areas, as has been demonstrated with young adults in other go/no-go and response inhibition tasks (Casey, Castellanos, et al., 1997; Casey, Trainor, et al., 1997; Chao \& Knight, 1997; Garavan et al., 1999; Kawashima et 
al., 1996; Konishi, Nakajima, Uchida, Kameyama, et al., 1998;

Konishi, Nakajima, Uchida, Sekihara, et al., 1998; Konishi et al., 1999;

Tsujimoto et al., 1997). The difference between the circuit of

activation for target response (e.g., precentral gyrus, SMA proper) and

that for lures (e.g., relatively more anterior prefrontal areas) underscores the specificity of these prefrontal regions in inhibitory control.

The hypothesis that older adults would exhibit additional activation beyond that of young participants was also supported. Older adults had extensive left hemisphere, and in particular left lateral prefrontal, activation that was significantly greater than that seen in young adults during successful inhibitions. Relative to young adults, older participants in Part 1 had only a few areas of significantly reduced activation during response to targets and inhibition. Moreover, examining only older adults (Part 2), the older group comparably activated the same right hemisphere circuitry as the younger elders during inhibition, with extensive additional activation and no areas of significant reduction relative to younger elders.

The functional inhibition findings suggest that older adults can compensate for declining performance by the use of additional ipsilateral and contralateral brain regions. The recruitment view posits the use of additional, principally homologous (i.e., contralateral) circuitry for compensation (e.g., Cabeza et al., 1997), whereas the reorganization view would predict the activation of alternative circuitry for compensation (e.g., Della-Maggiore et al., 2000; Grady, 1998). Given that our older participants comparably activated the same regions as those activated by young adults, along with activation of additional homologous areas, recruitment may be the most parsimonious interpretation of our results.

Previous PET studies with perceptual and memory tasks have found similar evidence of compensation in elders, though mostly in conjunction with reduced activation in other areas (e.g., Backman et al., 1997; Cabeza et al., 1997, 2000; Grady et al., 1995, 1998; Madden et al., 1999; Nagahama et al., 1997; Reuter-Lorenz et al., 2000). The event-related procedure used in this study, which allows removal of error trials, may have reduced error-based contributions to the functional maps, resulting in less evidence of age-related

Psychology and Aging, Vol 17, No. 1 (March 2002): pg. 56-71. DOI. This article is (c) American Psychological Association and permission has been granted for this version to appear in e-Publications@Marquette. American Psychological Association does not grant permission for this article to be further copied/distributed or hosted elsewhere without the express permission from American Psychological Association. 
activation reductions. In contrast, task differences may also be responsible for the between-study differences. On a cautionary note, in addition to removing error-based contributions to functional maps, removal of error trials from analysis typically leaves fewer trials for analysis for older participants than for young ones. Indeed, 2 of our participants performed rather poorly, leaving only seven lure trials for analysis. Either including or excluding such participants from analysis can have an effect on the results. We chose to include them because the effect of task performance was of particular interest. In any event, the current study highlights the utility of the event-related procedure in the study of aging using functional neuroimaging.

The predominance of prefrontal activation and compensation during this task is not surprising because inhibitory ability is associated with prefrontal function (e.g., Casey, Trainor, et al., 1997; Garavan et al., 1999; Grafman, 1995; Humberstone et al., 1997; Konishi, Nakajima, Uchida, Kameyama, et al., 1998; Tsujimoto et al., 1997) and because the frontal lobes are perhaps most affected by aging (e.g., Creasey \& Rapoport, 1985; Huttenlocher, 1979; ЦLacobs \& Scheibel, 1993; Terry, DeTeresa, \& Hansen, 1987). Thus, diffuse prefrontal losses in older adults may be the source of greater overall prefrontal activation during successful inhibitions. The current task and similar response inhibition (e.g., go/no-go) tasks are most associated with right lateral prefrontal activation (e.g., Casey, Castellanos, et al., 1997; Casey, Trainor, et al., 1997; Garavan et al., 1999; Kawashima et al., 1996; Konishi, Nakajima, Uchida, Kameyama, et al., 1998; Konishi, Nakajima, Uchida, Sekihara, et al., 1998; Konishi et al., 1999), a result consistent with our data. Tasks that are particularly more dependent on verbal mechanisms, such as those with verbal interference (e.g., Stroop) or response competition, typically also find prefrontal activation, but on the left side (e.g., D'Esposito, Postle, Jonides, \& Smith, 1999; Jonides et al., 1998, 2000; Perret, 1974; Reuter-Lorenz et al., 2000; Smith et al., 1998; Taylor, Kornblum, Lauber, Minoshima, \& Koeppe, 1997). In several of these studies, the inhibition or interference component has been particularly associated with ventrolateral activation, such as in inferior frontal gyrus (e.g., D'Esposito, Postle, et al., 1999; Garavan et al., 1999; Konishi, Nakajima, Uchida, Kameyama, et al., 1998; Konishi, Nakajima, Uchida, Sekihara, et al., 1998; Konishi et al., 1999; Taylor et al., 1997). In this study, both dorsolateral and ventrolateral activation

Psychology and Aging, Vol 17, No. 1 (March 2002): pg. 56-71. DOI. This article is (c) American Psychological Association and permission has been granted for this version to appear in e-Publications@Marquette. American Psychological Association does not grant permission for this article to be further copied/distributed or hosted elsewhere without the express permission from American Psychological Association. 
were found to be associated with response inhibition, but ventrolateral regions were perhaps most notable. The relative consistency among these studies highlights the advantages of the event-related paradigm for revealing specific regional activation-associated task subcomponents, such as the common role of response inhibition or interference in working memory (e.g., D'Esposito, Postle, et al., 1999).

The task used in the present study is somewhat more complex than some other go/no-go tasks, but it has been used previously with comparable results to those other tasks (Garavan et al., 1999). Specifically, the task used here includes a small working memory component in that the identity of the previous target must be retained to make a response decision to the next target. Thus, it is similar to a working memory " $n$-back" task where $n$ is equal to one item. Importantly, this task is distinguishable from an n-back task because it establishes and maintains prepotency to respond when inhibition is necessary, and because the working memory load does not transiently increase during lure presentation inasmuch as no updating of the contents of working memory for the current target is necessary during lure presentation. However, it might be useful to consider how the activations attributable to such a task as this one differ from more traditional n-back tasks.

Most $n$-back tasks produce activation in multiple prefrontal regions that are comparable to those we found. Indeed, increasing load in these tasks can generate greater activation within these regions (cf. Cabeza \& Nyberg, 2000) as well as in contralateral areas (Klingberg, O'Sullivan, \& Roland, 1997; Stuss et al., 1999). However, few studies have examined the $n=1$ condition relative to control (or $n$ $=0$ ), which would be most comparable to the current task. Where it has been examined, the $\mathrm{n}=1$ condition typically does not produce more extensive activation than does a control condition, which is consistent with its "low-load" designation (however, see Braver et al., 1997; D. C. Cohen et al., 1997). Furthermore, we also found specific activation areas in the inferior frontal gyrus, which are typically not found in traditional working memory tasks. Activation in this region is more specifically associated with inhibitory control tasks (e.g., D'Esposito, Postle, et al., 1999; Garavan et al., 1999; Konishi, Nakajima, Uchida, Kameyama, et al., 1998; Konishi, Nakajima, Uchida, Sekihara, et al., 1998; Konishi et al., 1999; Taylor et al.,

Psychology and Aging, Vol 17, No. 1 (March 2002): pg. 56-71. DOI. This article is (c) American Psychological Association and permission has been granted for this version to appear in e-Publications@Marquette. American Psychological Association does not grant permission for this article to be further copied/distributed or hosted elsewhere without the express permission from American Psychological Association. 
1997) or working memory tasks that specifically manipulate response prepotency (Jonides et al., 1998). It would be interesting to determine whether the areas "recruited" by elders in this inhibitory task are distinguishable from the areas "recruited" by young and older adults during working memory tasks with varying levels of difficulty. Such a question would be best addressed using a within-subject design using both types of tasks and a direct comparison of activation results. Regardless, similarity in the neural substrates for working memory and inhibitory control is not surprising in that both processes are critically important for much of cognitive functioning, and inhibition is of central importance to normal working memory performance because of the need to suppress interfering stimuli (e.g., Casey, Trainor, et al., 1997; see also Duncan \& Owen, 2000; Garavan et al., 1999; Pennington, 1994).

Additional left prefrontal activation in elders in this study can be interpreted in several ways. First, some studies suggest that when task demands are high, more prefrontal cortex in either hemisphere (or both hemispheres) is recruited to the task (Klingberg et al., 1997; Stuss et al., 1999). The task demands, both by performance and anecdotal report, were greater for older participants relative to younger ones. Indeed, increased left prefrontal activation (attributable primarily to older participants) was also correlated with slower reaction time, which may reflect recruitment inasmuch as an increase in task difficulty that leads to recruitment may cause a slowing of processing speed that causes slowed reaction time (Salthouse, 1996). It is also notable that there were increases in left prefrontal activation in both more dorsal sites and in those that are more specific to the inferior frontal gyrus that is associated with response inhibition. In addition, increased left prefrontal activity in elders could be reflective of their greater verbal strategy usage. This interpretation would fit with Stroop and other interference studies that show an association of inhibition with left rather than right prefrontal activation (e.g., D'Esposito, Postle, et al., 1999; Lonides et al., 1998, 2000; Perret, 1974; Smith et al., 1998; Taylor et al., 1997). However, this interpretation leaves unclear why the right prefrontal activation, which is predominantly comparable in young and old, that occurs with this task and compares with other response inhibition studies (e.g., Casey, Castellanos, et al., 1997; Casey, Trainor, et al., 1997; Garavan et al., 1999; Kawashima et al., 1996; Konishi, Nakajima, Uchida, Kameyama, et al., 1998;

Psychology and Aging, Vol 17, No. 1 (March 2002): pg. 56-71. DOI. This article is @ American Psychological Association and permission has been granted for this version to appear in e-Publications@Marquette. American Psychological Association does not grant permission for this article to be further copied/distributed or hosted elsewhere without the express permission from American Psychological Association. 
Konishi, Nakajima, Uchida, Sekihara, et al., 1998; Konishi et al., 1999) would be necessary. Finally, multiple studies using a variety of tasks have found more bilateral activity in elders compared with young adults, with which our results are consistent. Cabeza (2002) reviews these studies and introduces a new model, hemispheric asymmetry reduction in old adults (HAROLD), to account for the findings. Our data are consistent with the HAROLD model, which is itself consistent with a compensation view.

It should be noted that the construct of recruitment need not be restricted to engagement of contralateral regions. For example, evidence of recruitment by elders within-hemisphere has been found, such as elders engaging both dorsal and ventral streams during both what and where processing (e.g., Grady, Haxby, Horwitz, Schapiro, \& Rapoport, 1992; Grady et al., 1994). This type of finding highlights the lack of strong distinction between a recruitment or a reorganization interpretation. More important, what has yet to be investigated by any study, and is critical for any compensation view, is whether there is a direct benefit to the additional activity. Although one behavioral study that mandated bihemispheric processing by the manipulation of targets and probes in separate portions of the visual field suggested that increased bilateral activity in elders is beneficial, the authors acknowledged that direct evidence that links performance with activation areas is necessary to support this conclusion (ReuterLorenz, Stanczak, \& Miller, 1999). Future studies, perhaps examining error trials and correct trials, will be needed to definitively establish the link between recruitment and functional benefit.

Increased parietal activation in both hemispheres in older relative to younger participants was also found. I nferior parietal cortex was previously shown to be activated by this task (Garavan et al., 1999). Its role is thought to be in assisting in the fine motor control to retract (or prevent) the motor response (Garavan et al., 1999; Steinmetz, 1998), which is consistent with the correlation between activation here and task performance and speed. Additionally, inferior parietal cortex is associated with phonological short-term memory storage (cf. Cabeza \& Nyberg, 2000). Indeed, fronto-parietal networks are associated with working memory, and activation is influenced by working memory load (e.g., Klingberg et al., 1997). Although the present task does include a working memory component, it is minimal

Psychology and Aging, Vol 17, No. 1 (March 2002): pg. 56-71. DOI. This article is (c) American Psychological Association and permission has been granted for this version to appear in e-Publications@Marquette. American Psychological Association does not grant permission for this article to be further copied/distributed or hosted elsewhere without the express permission from American Psychological Association. 
(i.e., one item) and does not transiently increase during lure presentation. Greater inferior parietal activation in older participants may reflect the greater demand of the task on them. Alternatively, it might reflect the use of subvocalization to rehearse the expected target (e.g., during an $X$ lure presentation, the participant is subvocalizing $Y$ because he or she is awaiting a $Y$ as the next eligible target).

Some regions of activation provided evidence that the effects of inhibitory performance (or ability) on activation can be separated from that resulting from aging per se. In older adults (Part 2), activation in the right pre-SMA interacted with age and task performance such that poor performers had more activation than better performers had, an effect that was greatest in the eldest participants. For the left preSMA, there were main effects for both age and performance, in which activation was greatest in both the oldest participants and in the poorest performers in either age group. These findings support the role of pre-SMA in inhibition (e.g., Garavan et al., 1999; Humberstone et al., 1997). Additionally, studies with increasing task load demands (e.g., working memory) show that participants exhibit greater regional activation, or recruitment, when difficulty is high (Klingberg et al., 1997; Stuss et al., 1999). As such, similar to the recruitment interpretation for older versus younger individuals, our results could be interpreted as poorer performers increasing their use of these regions when the task is more difficult.

Decreased regional activation in association with poor task performance is sometimes interpreted as a failure of the region(s) to function sufficiently. For example, one PET study found that older adults exhibited greater working memory interference (i.e., poorer performance) and less activation in left lateral prefrontal areas than did young adults, presumably because the region functioned less well in older individuals (Ц onides et al., 2000). In addition, greater left hemisphere activation, particularly in posterior areas, has been associated with better task performance in elders (Reuter-Lorenz et al., 2000). It might seem then that the interpretation of increased activation in "poor performers" as recruitment conflicts with previous studies. However, consistent with our interpretation, a recent PET study found that with increased executive demands (e.g., dual tasks), poorer young performers and older participants had left prefrontal

Psychology and Aging, Vol 17, No. 1 (March 2002): pg. 56-71. DOI. This article is (c) American Psychological Association and permission has been granted for this version to appear in e-Publications@Marquette. American Psychological Association does not grant permission for this article to be further copied/distributed or hosted elsewhere without the express permission from American Psychological Association. 
activation, whereas good young performers did not (Smith et al., 2001). Furthermore, it must be emphasized that the activation data for the current event-related study are taken only from successful trials, and as such "poor performers" and "good performers" were equivalent in actual performance in terms of the imaging data. Thus, when both groups are performing accurately, greater activation may reflect compensation. An alternative interpretation of a negative association between regional activation and task performance, however, is that the "recruitment" is disruptive, rather than beneficial, perhaps itself reflecting failed inhibition (Cabeza et al., 1997). That is, although the prominent interpretation is that poorer performers, on successful trials, would have greater activation as compensation, one could instead interpret it as interfering with performance. Thus, if it could be suppressed, performance would be improved. It will be difficult to differentiate between these possibilities because of the correlational nature of these associations. However, future studies that compare activation during successful trials with activation during error trials might provide some clarification.

In conclusion, this study supports many existing studies that show that inhibitory decline occurs in advancing age and that this decline may be associated with other cognitive changes (e.g., Hasher \& Zacks, 1988). Response inhibition was associated with predominantly right lateralized prefrontal and parietal activation. In addition, advanced age and poor inhibitory control were associated with additional activation within the right hemisphere as well as in left prefrontal and parietal areas. The results support the view that older adults compensate for age-related neural changes by recruiting additional neural circuitry to assist with inhibition, but whether this recruitment is directly beneficial to performance must still be investigated.

\section{$\underline{\text { References }}$}

Aguirre, G. K., Zarahn, E., \& D'Esposito, M. (1998). The variability of human BOLD hemodynamic responses. Neurol mage, 8, 360-369.

Allison, T., McCarthy, G., Nobre, A., Puce, A., \& Belger, A. (1994). Human extrastriate visual cortex and the perception of faces, words, numbers, and colors. Cerebral Cortex, 4(5), 544-554.

Psychology and Aging, Vol 17, No. 1 (March 2002): pg. 56-71. DOI. This article is @ American Psychological Association and permission has been granted for this version to appear in e-Publications@Marquette. American Psychological Association does not grant permission for this article to be further copied/distributed or hosted elsewhere without the express permission from American Psychological Association. 
Arbuckle, T., \& Gold, D. (1993). Aging, inhibition, and verbosity. Journal of Gerontology: Psychological Science, 48, 225-282.

Backman, L., Almkvist, O., Andersson, J., Nordberg, A., Windblad, B., Rineck, R., \& Lagstrom, B. (1997). Brain actiation in young and older adults during implicit and explicit retrieval. Journal of Cognitive Neuroscience, 9(3), 378-391.

Barkley, R. A. (1997). Behavioral inhibition, sustained attention and executive functions: Constructing a unifying theory of ADHD. Psychological Bulletin, 121, 65-94.

Benton, A., Eslinger, P., \& Damasio, A. (1981). Normative observations on neuropsychological test performance in old age. Journal of Clinical Neuropsychology, 3, 33-42.

Bjorklund, D. F., \& Harnishfeger, K. K. (1995). The evolution of inhibition mechanisms and their role in human cognition and behavior. In $\mathrm{F}$. N.Dempster \& C. J.Brainerd (Eds.), Interference and inhibition in cognition (pp. 141-173). San Diego, CA: Academic Press.

Brainerd, C., \& Reyna, V. (1993). Memory independence and memory interference. Psychological Review, 100, 42-67.

Braver, T. S., Cohen, J. D., Nystrom, L. E., Jonides, J., Smith, E. E., \& Noll, D. C. (1997). A parametric study of prefrontal cotex involvement in human working memory. Neurol mage, 5(1), 49-62.

Butters, N., Butters, C., Rosen, J., \& Stein, D. (1973). Behavioral effects of sequential and one-stage ablations of orbital prefrontal cortex in the monkey. Experimental Neurology, 39, 204-214.

Cabeza, R. (2002). Hemispheric asymmetry reduction in older adults: The HAROLD model. Psychology and Aging, 17, 85-100.

Cabeza, R., Anderson, N. D., Houle, S., Mangels, J. A., \& Nyberg, L. (2000). Age-related differences in neural activity during item and temporalorder memory retrieval: A positron emission tomography study. Journal of Cognitive Neuroscience, 12(1), 197-206.

Cabeza, R., Grady, C., Nyberg, L., Mclntosh, A., Tulving, E., \& Kapur, S. (1997). Age-related differences in neural activity during memory encoding and retrieval: A positron emission tomography study. Journal of Neuroscience, 17(1), 391-400.

Cabeza, R., \& Nyberg, L. (2000). Imaging cognition II: An empirical review of 275 PET and fMRI studies. Journal of Cognitive Neuroscience, 12(1), $1-47$.

Casey, B., Castellanos, F., Giedd, J., Marsh, W., Hamburger, S., \& Schubert, A. (1997). Implication of the right frontostriatal circuitry in response inhibition and attention-deficit/hyperactivity disorder. Journal of the American Academy of Child and Adolescent Psychiatry, 36(3), 374383.

Psychology and Aging, Vol 17, No. 1 (March 2002): pg. 56-71. DOI. This article is (c) American Psychological Association and permission has been granted for this version to appear in e-Publications@Marquette. American Psychological Association does not grant permission for this article to be further copied/distributed or hosted elsewhere without the express permission from American Psychological Association. 
Casey, B., Trainor, R., Orendi, J., Schubert, A., Nystrom, L., \& Giedd, J. (1997). A developmental functional MRI study of prefrontal activation during performance of a go/no-go task. Journal of Cognitive Neuroscience, 9(6), 835-847.

Chao, L. L., \& Knight, R. T. (1997). Prefrontal deficits in attention and inhibitory control with aging. Cerebral Cortex, 7, 63-69.

Cohen, D. C., Perlstein, W. M., Brfafver, T. S., Nystrom, L. E., Noll, D. C., Jonides, J., \& Smith, E. E. (1997, April). Temporal dynamics of brain activation during a working memory task. Nature, 386, 604-608.

Cohen, G. (1988). Age differences in memory for texts: Production deficiency or processing limitations?. In L. Light \& D.Burke (Eds.), Language, memory and aging (pp. 171-190). Cambridge, England: Cambridge University Press.

Cohen, M. (1997). Parametric analysis of fMRI signal using linear systems methods. Neurol mage, 6, 93-103.

Cohen, N., Dustman, R., \& Bradford, D. (1984). Age related decrements in Stroop color test performance. J ournal of Clinical Psychology, 40, 1244- 1250.

Cox, R. (1996). AFNI: Software for analysis and visualization of functional magnetic resonance neuroimages. Computers in Biomedical Research, 29, 162-173.

Craik, F. I. M., \& Salthouse, T. (Eds.). (1992). Handbook of aging and cognition. Hillsdale, $\mathrm{NJ}$ : Erlbaum.

Creasey, H., \& Rapoport, S. I. (1985). The aging human brain. Annals of Neurology, 17(1), 2-10.

Della-Maggiore, V., Sekuler, A. B., Grady, C. L., Bennett, P., Sekuler, R., \& Mclntosh, A. R. (2000). Corticolimbic interactions associated with performance on a short-term memory task are modified by age. Journal of Neuroscience, 20, 8410-8416.

Dempster, F. (1993). Resistance to interference: Developmental changes in basic processing mechanisms. In R. P. M.Howe (Ed.), Emerging themes in cognitive development: Vol. 1. Foundations (pp. 3-27). New York: Springer-Verlag.

Dempster, F., \& Brainerd, C. (1995). Interference and inhibition in cognition. San Diego, CA: Academic Press.

D'Esposito, M., Postle, B. R., Jonides, J., \& Smith, E. E. (1999). The neural substrate and temporal dynamics of interference effects in working memory as revealed by event-related functional MRI. Proceedings of the National Academy of Sciences, USA, 96(13), 7514-7519.

D'Esposito, M., Zarahn, E., Aguirre, G. K., \& Rypma, B. (1999). The effect of normal aging on the coupling of neural activity to the BOLD hemodynamic response. Neurolmage, 10, 6-14.

Psychology and Aging, Vol 17, No. 1 (March 2002): pg. 56-71. DOI. This article is @ American Psychological Association and permission has been granted for this version to appear in e-Publications@Marquette. American Psychological Association does not grant permission for this article to be further copied/distributed or hosted elsewhere without the express permission from American Psychological Association. 
NOT THE PUBLISHED VERSION; this is the author's final, peer-reviewed manuscript. The published version may be

accessed by following the link in the citation at the bottom of the page.

Diamond, A. (1990). The development and neural bases of memory functions, as indexed by the $A B$ and delayed response tasks, in human infants and infant monkeys. Annals of the New York Academy of Sciences, 608, 267-317.

Duncan, J., Johnson, R., Swales, M., \& Freer, C. (1997). Frontal lobe deficits after head injury: Unity and diversity of function. Cognitive Neuropsychology, 14, 713-741.

Duncan, J., \& Owen, A. M. (2000). Common regions of the human frontal lobe recruited by diverse cognitive demands. Trends in Neurosciences, 23(10), 475-483.

Enright, S. J., \& Beech, A. R. (1993). Reduced cognitive inhibition in obsessive-compulsive disorder. British Journal of Clinical Psychiatry, 32, 67-74.

Folstein, M. F., Folstein, S. E., \& McHugh, P. R. (1975). “Mini-Mental State”: A practical method for grading the cognitive state of patients for the clinician. Journal of Psychiatric Research, 12(3), 189-198.

Forman, S. D., Cohen, J. D., Fitzgerald, M., Eddy, W. F., Mintun, M. A., \& Noll, D. C. (1995). Improved assessment of significant activation in functional magnetic resonance imaging ( $f M R I)$ : Use of a cluster-size threshold. Magnetic Resonance Medicine, 33, 636-647.

Fox, E. (1995). Negative priming from ignored distractors in visual selection: A review. Psychonomic Bulletin and Review, 2, 145-173.

Garavan, H., Pankiewicz, J., Bloom, A., Cho, J.-K., Sperry, L., \& Ross, T. J . (2000). The neuroanatomical correlates of cue-induced cocaine craving and arousal. American J ournal of Psychiatry, 157(11), 1789-1798.

Garavan, H., Ross, T. J., \& Stein, E. A. (1999). Right hemispheric dominance of inhibitory control: An event-related fMRI study. Proceedings of the National Academy of Sciences, USA, 96, 8301-8306.

Grady, C. (1998). Brain imaging and age-related changes in cognition. Experimental Gerontology, 33(7), 661-673.

Grady, C. L., Haxby, J. V., Horwitz, B., Schapiro, M. B., \& Rapoport, S. I. (1992). Dissociation of object and spatial vision in human extrastriate cortex: Age-related changes in activation of regional cerebral blood flow measured with $\left[{ }^{15} \mathrm{O}\right]$ water and positron emission tomography. Journal of Cognitive Neuroscience, 4, 23-34.

Grady, C. L., Maisog, J. M., Horwitz, B., Ungerleider, L. G., Mentis, M. J., \& Salerno, J. A. (1994). Age-related changes in cortical blood flow activation during visual processing of faces and location. Journal of Neuroscience, 14, 1450-1462.

Grady, C. L., Mcl ntosh, A. R., Bookstein, F., Horwitz, B., Rapoport, S. I., \& Haxby, J. V. (1998). Age-related changes in regional cerebral blood flow during working memory for faces. Neurol mage, 8, 409-425.

Psychology and Aging, Vol 17, No. 1 (March 2002): pg. 56-71. DOI. This article is @ American Psychological Association and permission has been granted for this version to appear in e-Publications@Marquette. American Psychological Association does not grant permission for this article to be further copied/distributed or hosted elsewhere without the express permission from American Psychological Association. 
Grady, C. L., Mcl ntosh, A. R., Horwitz, B., Maisog, J. M., Ungerleider, L. G., \& Mentis, M. J. (1995, July14). Age-related reductions in human recognition memory due to impaired encoding. Science, 269, 218-221.

Grafman, J. (1995). Similarities and distinctions among current models of prefrontal cortex. In J.Grafman, K. Holyoak, \& F.Boller (Eds.), Structure and functions of the human prefrontal cortex (pp. 337-368). New York: New York Academy of Sciences.

Haaland, K., Vranes, L., Goodwin, J., \& Garry, P. (1987). Wisconsin Card Sort performance in a healthy elderly population. Journal of Gerontology, 42, 345- 346.

Hamm, V., \& Hasher, L. (1992). Age and the availability of inferences. Psychology and Aging, 7, 56-64.

Hartman, M., \& Hasher, L. (1991). Aging and suppresion: Memory for previously relevant information. Psychology and Aging, 6, 587-594.

Hasher, L., \& Zacks, R. (1988). Working memory, comprehension and aging: A review and a new view. The Psychology of Learning and Motivation, 22, 193-225.

Hashtroudi, S., Johnson, M., \& Chrosniak, L. (1990). Aging and qualitative characteristics of memories for perceived and imagined complex events. Psychology and Aging, 5, 119-126.

Houx, P., Jolles, J., \& Vreling, F. (1993). Stroop interference: Aging effects assessed with the Stroop color-word test. Experimental Aging Research, 19, 209-224.

Humberstone, M., Sawle, G., Clare, S., Hykin, J., Coxon, R., \& Bowtell, R. (1997). Functional magnetic resonance imaging of single motor events reveals human presupplementary motor area. Annals of Neurology, 42, 632- 637.

Huttenlocher, P. R. (1979). Synaptic density in human frontal cortex: Developmental changes and effects of aging. Brain Research, 163, 195-205.

Iverson, S., \& Mishkin, M. (1970). Perseverative interference in monkeys following selective lesions of the inferior prefrontal convexity. Experimental Brain Research, 11, 376-386.

Jacobs, B., \& Scheibel, A. (1993). A quantitative dendritic analysis of Wernicke's area in humans: I. Lifespan changes. Journal of Comparative Neurology, 327(1), 83-96.

Jonides, J., Marshuetz, C., Smith, E. E., Reuter-Lorenz, P., Koeppe, R. A., \& Hartley, A. (2000). Age differences in behavior and PET activation reveal differences in interference resolution in verbal working memory. Journal of Cognitive Neuroscience, 12(1), 188- 196.

Jonides, J., Smith, E., Marshuetz, C., Koeppe, R., \& Reuter-Lorenz, P. (1998). Inhibition in verbal working memory revealed by brain activation.

Psychology and Aging, Vol 17, No. 1 (March 2002): pg. 56-71. DOI. This article is (c) American Psychological Association and permission has been granted for this version to appear in e-Publications@Marquette. American Psychological Association does not grant permission for this article to be further copied/distributed or hosted elsewhere without the express permission from American Psychological Association. 
Proceedings of the National Academy of Sciences, USA, 95(14), 84108413.

Kausler, D., \& Hakami, M. (1982). Frequency judgments for young and elderly adults for relevant stimuli with simultaneously present irrelevant stimuli. Journal of Gerontology, 37, 438-442.

Kawashima, R., Satoh, K., Itoh, H., Ono, S., Furumoto, S., \& Gotoh, R. (1996). Functional anatomy of go/no-go discrimination and response selection-A PET study in man. Brain Research, 728, 79-89.

Kemper, R. (1994). Neuroanatomical and neuropathological changes in normal aging and in dementia. In M. L. Albert \& E. J. E. Knoepfel (Eds.), Clinical neurology of aging (2nd ed., (pp. 3-67). New York: Oxford University Press.

Kiehl, K. A., Kiddle, P. F., \& Hopfinger, J. B. (2000). Error processing and the rostral anterior cingulate: An event-related fMRI study. Psychophysiology, 37, 216-223.

Kieley, J. M., \& Hartley, A. A. (1997). Age-related equivalence of indentity suppression in the Stroop color-word task. Psychology and Aging, 12, 22- 29.

Klingberg, T., O'Sullivan, B. T., \& Roland, P. E. (1997). Bilateral activation of fronto-parietal networks by incrementing demand in a working memory task. Cerebral Cortex, 7(5), 465-471.

Konishi, S., Nakajima, K., Uchida, I., Kameyama, M., Nakahara, K., Sekihara, K., \& Miyashita, Y. (1998). Transient activation of inferior prefrontal cortex during cognitive set shifting. Nature Neuroscience, 1(1), 80-84.

Konishi, S., Nakajima, K., Uchida, I., Kikyo, H., Kameyama, M., \& Miyashita, Y. (1999). Common inhibitory mechanism in human inferior prefrontal cortex revealed by event-related functional MRI. Brain, 122, 981-991.

Konishi, S., Nakajima, K., Uchida, I., Sekihara, K., \& Miyashita, Y. (1998). No-go dominant brain activity in human inferior prefrontal cortex revealed by functional magnetic resonance imaging. European Journal of Neuroscience, 10, 1209-1213.

Kramer, A., Humphrey, D., Latish, J., Logan, G., \& Strayer, D. (1994). Aging and inhibition: Beyond a unitary view of inhibitory processing in attention. Psychology and Aging, 9, 491-512.

Leach, L., Warner, C., Hotz-Sud, R., Kaplan, E., \& Freedman, M. (1991). The effects of age on card sorting variables. Journal of Clinical and Experimental Neuropsychology, 13, 28.

Leimkuhler, M. E., \& Mesulam, M.-M. (1985). Reversible go/no-go deficits in a case of frontal lobe tumor. Annals of Neurology, 18, 617-619.

Lezak, M. D. (1995). Neuropsychological assessment (3rd ed.). New York: Oxford University Press.

Light, L. L. (1996). Memory and aging. In E. L.Bjork \& R. A.Bjork (Eds.), Memory (2nd ed., (pp. 443-490). San Diego, CA: Academic Press.

Psychology and Aging, Vol 17, No. 1 (March 2002): pg. 56-71. DOI. This article is @ American Psychological Association and permission has been granted for this version to appear in e-Publications@Marquette. American Psychological Association does not grant permission for this article to be further copied/distributed or hosted elsewhere without the express permission from American Psychological Association. 
NOT THE PUBLISHED VERSION; this is the author's final, peer-reviewed manuscript. The published version may be

accessed by following the link in the citation at the bottom of the page.

Little, D. M., \& Hartley, A. A. (2000). Further evidence that negative priming in the Stroop color-word task is equivalent in older and younger adults. Psychology and Aging, 15, 9- 17.

Madden, D. J., \& Hoffman, J. M. (1997). Application of positron emission tomography to age-related cognitive changes. In K. R. R. Krishman \& P. M.Doraiswamy (Eds.), Brain imaging in clinical psychiatryNew York: Marcel Dekker.

Madden, D. J., Turkington, T., Provenzale, J., Denny, L., Hawk, T., \& Gottlob, L. (1999). Adult age differences in the functional neuroanatomy of verbal recognition memory. Human Brain Mapping, 7, 115-135.

Madden, D. J., Turkington, T. G., Provenzale, J. M., Hawk, T. C., Hoffman, J. M., \& Coleman, R. E. (1997). Selective and divided visual attention: Age-related changes in regional cerebral blood flow measured by M2150 PET. Human Brain Mapping, 5, 389-409.

McDowd, J., \& Filion, D. (1992). Aging, selective attention, and inhibitory processes: A psychophysiological approach. Psychology and Aging, 7, 65- 71.

McDowd, J., \& Oseas-Kreger, D. (1991). Aging, inhibitory processes, and negative priming. Journal of Gerontology: Psychological Sciences, 46, 340-345.

McDowd, J. M., Oseas-Kreger, D. M., \& Filion, D. L. (1995). Inhibitory processes in cognition and aging. In F. N.Dempster \& C. J.Brainerd (Eds.), Interference and inhibition in cognition (pp. 363-400). San Diego, CA: Academic Press.

Misanin, J., Blatt, L., \& Hinderliter, C. (1985). Age dependency in neophobia: Its influence on taste aversion learning and the flavor preexposure effect in rats. Animal Learning and Behavior, 13, 69-76.

Miyake, A., Friedman, N. P., Emerson, M. J., Witzki, A. H., \& Howerter, A. (2000). The unity and diversity of executive functions and their contributions to complex "frontal lobe" tasks: A latent variable analysis. Cognitive Psychology, 41, 49-100.

Moscovitch, M., \& Winocur, G. (1995). Frontal lobes, memory, and aging. In J.Grafman, K.Holyoak, \& F.Bohler (Eds.), Structure and functions of the human prefrontal cortex (pp. 119-150). New York: New York Academy of Sciences.

Nagahama, Y., Kukuyama, H., Yamaguchi, H., Katsumi, Y., Magata, Y., \& Shibasaki, H. (1997). Age-related changes in cerebral blood flow activation during a card sorting test. Experimental Aging Research, 114(3), 571-577.

Nielson, K. A., Garavan, H., Langenecker, S. A., Stein, E. A., \& Rao, E. A. (2001). Event-related fMRI of inhibitory control reveals lateralized prefrontal activation differences between healthy young and older

Psychology and Aging, Vol 17, No. 1 (March 2002): pg. 56-71. DOI. This article is @ American Psychological Association and permission has been granted for this version to appear in e-Publications@Marquette. American Psychological Association does not grant permission for this article to be further copied/distributed or hosted elsewhere without the express permission from American Psychological Association. 
adults. 10th Annual Conference of the Rotman Research Institute: The frontal lobes. Brain and Cognition, 47(1-2), 169-172.

Omori, M., Yamada, H., Murata, T., Sadato, N., Tanaka, M., \& I shii, Y. (1999). Neuronal substates participating in attentional set-shifting of rules for visually guided motor selection: A functional magnetic resonance imaging investigation. Neuroscience Research, 33(4), 317-323.

Panek, P., Rush, M., \& Slade, L. (1984). Locus of age-Stroop interference relationship. J ournal of Genetic Psychology, 145, 209-216.

Parkin, A., \& Walter, B. (1992). Recollective experience, normal aging and frontal dysfunction. Psychology and Aging, 7, 290-298.

Pennington, B. (1994). The working memory function of the prefrontal cortexes. In J. B. M. Haith, R.Roberts, \& B.Pennington (Eds.), Development of future oriented processes (pp. 243-289). Chicago: University of Chicago Press.

Perret, E. (1974). The left frontal lobe of man and the suppression of habitual responses in verbal categorical behavior. Neuropsychologia, 12(3), 323-330.

Peterson, B. S., Skudlarski, P., Anderson, A. W., Zhang, H., Gatenby, J. C., \& Lacedie, C. M. (1998). A functional magnetic resonance imaging study of tic suppression in Tourette's syndrome. Archives of General Psychiatry, 55, 326-333.

Picard, N., \& Strick, P. L. (1996). Motor areas of the medial wall: A review of their location and functional activation. Cerebral Cortex, 6, 342-353.

Raz, N. (2000). Aging of the brain and its impact on cognitive performance: Integration of structural and functional findings. In F. I. M.Craik \& T. A.Salthouse (Eds.), Handbook of aging and cognition (2nd ed., (pp. 190). Mahwah, NJ: Erlbaum.

Raz, N., Gunning, F. M., Head, D., Dupuis, J. H., McQuain, J., \& Briggs, S. D. (1997). Selective aging of the human cerebral cortex observed in vivo: Differential vulnerability of the prefrontal gray matter. Cerebral Cortex, 7(3), 268-282.

Reuter-Lorenz, P. A., Jonides, J., Smith, E. E., Hartley, A., Miller, A., Marshuetz, C., \& Koeppe, R. A. (2000). Age differences in the frontal lateralization of verbal and spatial working memory revealed by PET. Journal of Cognitive Neuroscience, 12(1), 174- 187.

Reuter-Lorenz, P. A., Stanczak, L., \& Miller, A. C. (1999). Neural recruitment and cognitive aging: Two hemispheres are better than one, especially as you age. Psychological Science, 10(6), 494-500.

Rypma, B., \& D'Esposito, M. (2000). I solating the neural mechanisms of agerelated changes in human working memory. Nature Neuroscience, 3(5), 509-515.

Salthouse, T. (1996). The processing speed theory of adult age differences in cognition. Psychological Review, 103, 403-428.

Psychology and Aging, Vol 17, No. 1 (March 2002): pg. 56-71. DOI. This article is (c) American Psychological Association and permission has been granted for this version to appear in e-Publications@Marquette. American Psychological Association does not grant permission for this article to be further copied/distributed or hosted elsewhere without the express permission from American Psychological Association. 
Sheikh, J. I., \& Yesavage, J. A. (1986). Geriatric Depression Scale (GDS): Recent evidence and development of a shorter version. Clinical Gerontologist, 15(1-2), 165-173.

Smith, E. E., Geva, A., Jonides, J., Miller, A., Reuter-Lorenz, P., \& Koeppe, R. A. (2001). The neural basis of task-switching in working memory: Effects of performance and aging. Proceedings of the National Academy of Sciences, USA, 98(4), 2095-2100.

Smith, E. E., Jonides, J., Marshuetz, C., \& Koeppe, R. (1998). Components of verbal working memory: Evidence from neuroimaging. Proceedings of the National Academy of Sciences, USA, 95(3), 876-882.

Steinmetz, M. A. (1998). Contribution of posterior parietal cortex to cognitive functions in primates. Psychobiology, 26, 109-118.

Stuss, D. T., Toth, J. P., Franchi, D., Alexander, M. P., Tipper, S., \& Craik, F. I. M. (1999). Dissociation of attentional processes in patients with focal frontal and posterior lesions. Neuropsychologia, 37(9), 10051027.

Talairach, J., \& Tournoux, P. (1988). Co-planar stereotaxic atlas of the human brain. New York: Thieme.

Taylor, S., Kornblum, S., Lauber, E., Minoshima, S., \& Koeppe, R. (1997). I solation of specific interference processing in the Stroop task: PET activation studies. Neurol mage, 6, 81-92.

Terry, R. D., DeTeresa, R., \& Hansen, L. A. (1987). Neocortical cell counts in normal human adult aging. Annals of Neurology, 21, 530-539.

Teuber, H.-L. (1972). Unity and diversity of frontal lobe functions. Acta Neurobiologiae Experimentalis, 32, 615-656.

Tsujimoto, T., Ogawa, M., Nishikawa, S., Tsukada, H., Kakiuchi, T., \& Sasaki, K. (1997). Activation of the prefrontal, occipital and parietal cortices during go/no-go discrimination tasks in the monkey as revealed by positron emission tomography. Neuroscience Letters, 224, 111-114.

Verhaeghen, P., \& de Meersman, L. (1998). Aging and the Stroop effect: A meta-analysis. Psychology and Aging, 13, 120-126.

Vorobiev, V., Bovoni, P., Rizzolatti, G., Metelli, M., \& Luppino, G. (1998). Parcellation of human mesial area 6: Cytoarchitectonic evidence for three separate areas. European J ournal of Neuroscience, 10(6), 21992203.

Ward, B., Garavan, H., Ross, T., Bloom, A., Cox, R., \& Stein, E. (1998, June). Nonlinear regression for fMRI time series analysis. Paper presented at the 4th International Conference on Functional Mapping of the Human Brain, Montreal, Quebec, Canada.

West, R. L. (1996). An application of prefrontal cortex function theory to cognitive aging. Psychological Bulletin, 120, 272-292.

Wong, E., Buskamp, E., \& Hyde, J. (1992, August). A volume optimized quadrature elliptical endcap birdcage brain coil.Paper presented at the

Psychology and Aging, Vol 17, No. 1 (March 2002): pg. 56-71. DOI. This article is (c) American Psychological Association and permission has been granted for this version to appear in e-Publications@Marquette. American Psychological Association does not grant permission for this article to be further copied/distributed or hosted elsewhere without the express permission from American Psychological Association. 
NOT THE PUBLISHED VERSION; this is the author's final, peer-reviewed manuscript. The published version may be accessed by following the link in the citation at the bottom of the page.

11th Annual Scientific Meeting, Society for Magnetic Resonance Medicine, Berlin, Germany.

Woodruff-Pak, D. S. (1997). The neuropsychology of aging. Oxford, England: Basil Blackwell.

Psychology and Aging, Vol 17, No. 1 (March 2002): pg. 56-71. DOI. This article is (c) American Psychological Association and permission has been granted for this version to appear in e-Publications@Marquette. American Psychological Association does not grant permission for this article to be further copied/distributed or hosted elsewhere without the express permission from American Psychological Association. 